\title{
Influence of trans fatty acids on glucose metabolism in soleus muscle of rats fed diets enriched in or deprived of linoleic acid
}

\author{
Ana C. Fariña ${ }^{1}$ Sandro Hirabara ${ }^{2} \cdot$ Juliana Sain $^{1,3}$ • Marcela González ${ }^{1}$. \\ Rui Curi $^{4,5} \cdot$ Claudio Bernal ${ }^{1,3}$ (1)
}

Received: 6 December 2016 / Accepted: 19 February 2017

(C) Springer-Verlag Berlin Heidelberg 2017

\begin{abstract}
Purpose Industrial trans fatty acid (TFA) intake leads to impaired glucose metabolism. However, the overall effects reported are inconsistent and vary with the dietary FA composition and TFA isomer type and levels. We investigated TFA effects on glucose uptake, incorporation and oxidation, and glycogen synthesis in incubated soleus muscle under basal conditions or after treatment with insulin and/or palmitate.

Methods Male Wistar rats were fed either linoleic acid (LA)-enriched ( $\left.{ }^{+} \mathrm{LA}\right)$ or LA-deprived ( $\left.{ }^{-} \mathrm{LA}\right)$ diet, supplemented $\left({ }^{+} \mathrm{LA}+\mathrm{TFA}\right.$ or $\left.{ }^{-} \mathrm{LA}+\mathrm{TFA}\right)$ or not with TFA, for 60 days. Soleus muscle glucose metabolism was assessed in the absence or presence of insulin and/or palmitic acid.

Results Under basal conditions, TFA enhanced glucose uptake and oxidation regardless of the LA status. Both
\end{abstract}

Ana C. Fariña and Sandro Hirabara contributed equally to this work.

Claudio Bernal

cbernal@fbcb.unl.edu.ar

1 Cátedra Bromatología y Nutrición, Facultad de Bioquímica y Ciencias Biológicas, Universidad Nacional del Litoral, C.C. 242, 3000 Santa Fe, Argentina

2 Institute of Physical Activity Sciences and Sports, Cruzeiro do Sul University, Sao Paulo, Brazil

3 Consejo Nacional de Investigaciones Científicas y Técnicas (CONICET), Santa Fe, Argentina

4 Department of Physiology and Biophysics, Institute of Biomedical Sciences, University of Sao Paulo, Sao Paulo, Brazil

5 Post-Graduate Program in Human Health Sciences, Biological Sciences and Health Center, Cruzeiro do Sul University, Sao Paulo, Brazil
TFA-supplemented groups had lower insulin response to glucose metabolism. Under insulin-stimulated conditions, TFA prevented the palmitate inhibition of muscle glucose uptake and metabolism in the ${ }^{+} \mathrm{LA}+$ TFA group.

Conclusion Dietary TFA enhanced glucose utilization in incubated soleus muscle under basal conditions and prevented the palmitate-induced inhibition in insulinstimulated conditions. However, TFA reduced the insulin response to glucose uptake and metabolism. The effects mentioned above were influenced by the FA profile modifications induced by the dietary LA levels, suggesting that lipid metabolization and incorporation into plasma membrane are important determining factors of glucose metabolism and insulin sensitivity.

Keywords Trans fatty acids - Linoleic acid - Glucose uptake - Glucose incorporation - Glucose oxidation . Glycogen synthesis

\section{Introduction}

In the last century, the human population, especially in Western countries, has drastically increased the consumption of vegetable oils rich in linoleic acid (LA; $9 c, 12 c-18: 2$, $n$-6) with a parallel decrease of those rich in $\alpha$-linolenic acid (ALA; $9 c, 12 c, 15 c-18: 3$ ), increasing the $\mathrm{n}-6: \mathrm{n}-3$ fatty acid (FA) ratio to $15-50: 1$ [1]. The high n-6:n-3 FA ratio has been associated with impaired serum lipid levels, unbalanced eicosanoid production, and metabolic syndrome [2, 3]. On the other hand, LA-deficient animals exhibit several lipid alterations [4] as well as changes in FA composition and fat accretion in the liver [5].

It has been reported that high intake of industrial trans fatty acids (TFA) leads to body fat accretion and 
hepatomegaly [6-9]. Furthermore, impaired glucose metabolism has been attributed to high chronic TFA intake. Several experiments in rats and monkeys have repeatedly reported that TFA have adverse effects on markers of insulin resistance compared with cis-monounsaturated FA and even saturated FA [10-12]. In this regard, various studies have been carried out but discrepant results and controversial conclusions have been reported. Nevertheless, the dietary FA composition and the different TFA isomers present in the experimental diets and/or tissues have been shown to be the determining factors. The 11t-18:1, in opposition to other $t-18: 1$ isomers, has a beneficial effect on glucose metabolism in rats probably through its bioconversion to 9c,11t-CLA [13-17].

Limited information exists about the TFA effects on the regulatory mechanisms of muscle glucose metabolism. Previously, we have described that TFA does not alter triacylglycerol (TG) content nor glucose-derived metabolite levels in gastrocnemius muscle [8]. In contrast, other authors [18] have described that TFA increases the intramyocellular TG content in diaphragm and this effect is associated with a decrease in the insulin-stimulated glucose transport.

Under normal conditions, insulin increases glucose uptake and metabolism in skeletal muscle by increasing the glucose transporter- 4 translocation from the intracellular vesicles to the plasma membrane [19]. However, these effects are significantly impaired under insulin resistance conditions, including obesity, type 2 diabetes mellitus, metabolic syndrome, and certain cardiovascular diseases [20, 21]. The mechanisms involved in the development of insulin resistance in skeletal muscle are not completely understood and some authors suggest that the elevated disposal of saturated nonesterified FA, such as palmitic and stearic acids, is involved [22-24]. To the best of our knowledge, the effects of TFA on the palmitate-induced insulin resistance in skeletal muscle remain unknown. Therefore, we decided to investigate this possibility in the present work.

Several of the metabolic dysfunctions caused by TFA mentioned above are associated with alterations of the long-chain polyunsaturated fatty acid (LC-PUFA) biosynthesis [24, 25], which could be impaired in essential fatty acid (EFA) deficiency or unbalances of the n-6:n-3 FA ratio [26]. Recently, we have reported that the nutritional and metabolic TFA effects are associated with changes in the FA profile induced by dietary LA levels and, to a lesser extent, with the specific type of isomer incorporated in the tissues. The aim of this study was to investigate the TFA effects on glucose uptake, incorporation, and oxidation, as well as glycogen synthesis in the incubated soleus muscle of rats fed a diet either enriched in or deprived of LA in basal conditions and under treatment with insulin and/or palmitate, two key modulators of glucose metabolism in skeletal muscle.

\section{Materials and methods}

\section{Materials}

Nutrients and other chemical compounds, vitamins and minerals for the diet preparations, were of chemical grade or better, with the exception of corn oil (Arcor, Córdoba, Argentina), hydrogenated coconut oil without TFA (Castoroil, Buenos Aires, Argentina), partially hydrogenated soybean oil $(-50 \%$ of TFA- Calsa, Buenos Aires, Argentina), sucrose, cellulose, and corn starch, which were obtained from local sources. Corn oil was used as an unsaturated cis-FA source, rich in LA (51\% of total FA to resemble the FA composition of the Western diet). Coconut oil was used to produce a LA deficiency status and partially hydrogenated soybean oil was used as a TFA source. All solvents and reagents used for the FA quantification were of chromatography grade, and all other chemicals used were of at least American Chemical Society grade. The standard FA were purchased from Sigma Chemical Co. (St Louis, MO, USA). The glucose test kits were commercially obtained from the Sociedad de Bioquímicos (Santa $\mathrm{Fe}$, Argentina). The insulin used was Humulin R (U-100), which was acquired from Eli Lilly (Indianapolis, IN, USA). Amersham International (Bucks, UK) provided the 2-deoxy-[2,6- $\left.{ }^{3} \mathrm{H}\right] \mathrm{D}$-glucose and $\left[\mathrm{U}^{14} \mathrm{C}\right] \mathrm{D}$-glucose.

\section{Animals, diets, and experimental design}

The experimental procedures were approved by the Ethics Committee of the School of Biochemistry and by the Ethics Committee of the Institute of Biomedical Sciences, University of Sao Paulo. Both followed the Guide for the Care and Use of Laboratory Animals [27]. Male Wistar rats were housed in an animal facility under controlled conditions $\left(23 \pm 2{ }^{\circ} \mathrm{C}\right.$ and a 12-h light-dark cycle). After reaching $100-120 \mathrm{~g}$, animals were equally and randomly assigned to 1 of 4 weight-matched groups ( $n=6$ per group) and fed ad libitum, for 60 days, one of the following diets: enriched with LA $\left({ }^{+}\right.$LA), deprived of LA $\left({ }^{-}\right.$LA), ${ }^{+}$LA supplemented with TFA-enriched oil ( $\left.{ }^{+} \mathrm{LA}+\mathrm{TFA}\right)$, or ${ }^{-} \mathrm{LA}$ supplemented with TFA-enriched oil ('LA + TFA). The ingredient composition of the diets is presented in Table 1 . The diets were based on the American Institute of Nutrition ad hoc writing committee recommendation (AIN-93G) [28], except for the FA source that was based on AIN-76 [29]. All diets were isoenergetic, providing $16.6 \mathrm{~kJ} / \mathrm{g}$. The ${ }^{+} \mathrm{LA}$ diet contained $7 \%$ corn oil ( $15.6 \%$ of energy) as a dietary lipid source and it was considered the control group. In the ${ }^{-}$LA diet, the corn oil was replaced with $7 \%$ hydrogenated coconut oil. TFA supplementation was achieved by replacing $2 \%$ of corn oil $\left({ }^{+} \mathrm{LA}+\mathrm{TFA}\right)$ or $2 \%$ of coconut oil $\left({ }^{-} \mathrm{LA}+\mathrm{TFA}\right)$ with TFA-enriched oil. The only difference between the 
Table 1 Ingredients and FA composition of the experimental diets

\begin{tabular}{|c|c|c|c|c|}
\hline Ingredient $^{\mathrm{a}}$ & ${ }^{+} \mathrm{LA}$ & ${ }^{-} \mathrm{LA}$ & ${ }^{+} \mathrm{LA}+\mathrm{TFA}$ & ${ }^{-} \mathrm{LA}+\mathrm{TFA}$ \\
\hline Corn starch & 529.5 & 529.5 & 529.5 & 529.5 \\
\hline Casein & 200 & 200 & 200 & 200 \\
\hline Sucrose & 100 & 100 & 100 & 100 \\
\hline Fiber & 50 & 50 & 50 & 50 \\
\hline Vitamin mixture & 35 & 35 & 35 & 35 \\
\hline Mineral mixture & 10 & 10 & 10 & 10 \\
\hline L-Cysteine-L-methionine & 3.0 & 3.0 & 3.0 & 3.0 \\
\hline Choline & 2.5 & 2.5 & 2.5 & 2.5 \\
\hline \multicolumn{5}{|l|}{ Fat } \\
\hline Corn oil & 70 & 0 & 50 & 0 \\
\hline Coconut fat & 0 & 70 & 0 & 50 \\
\hline AGT-rich oil & 0 & 0 & 20 & 20 \\
\hline \multicolumn{5}{|l|}{ Fatty acid composition ${ }^{\mathrm{b}}$} \\
\hline $6: 0$ & ND & 0.49 & ND & 0.35 \\
\hline 8:0 & ND & 6.76 & ND & 4.83 \\
\hline 10:0 & ND & 5.64 & ND & 4.03 \\
\hline 11:0 & ND & 0.02 & ND & 0.01 \\
\hline 12:0 & ND & 47.67 & ND & 34.05 \\
\hline 13:0 & ND & 0.02 & ND & 0.01 \\
\hline 14:0 & 0.03 & 17.46 & 0.05 & 12.50 \\
\hline $16: 0$ & 12.21 & 9.21 & 11.88 & 9.74 \\
\hline 16:1 & 0.12 & ND & 0.09 & ND \\
\hline $17: 0$ & ND & ND & 0.02 & 0.02 \\
\hline 18:0 & 1.93 & 12.53 & 4.46 & 12.03 \\
\hline$(6-8) t-18: 1$ & ND & ND & 1.62 & 1.62 \\
\hline $9 t-18: 1(n-9)$ & ND & ND & 2.08 & 2.08 \\
\hline $10 t-18: 1$ & ND & ND & 3.05 & 3.05 \\
\hline $11 t-18: 1$ & ND & ND & 2.76 & 2.76 \\
\hline $12 t-18: 1(n-6)$ & ND & ND & 2.14 & 2.14 \\
\hline$(6-8) c+(13 / 14) t-18: 1$ & ND & ND & 2.36 & 2.36 \\
\hline $9 c-18: 1(\mathrm{n}-9)$ & 31.95 & 0.05 & 25.40 & 2.62 \\
\hline $15 t+10 c-18: 1$ & ND & ND & 1.13 & 1.13 \\
\hline $11 c-18: 1$ & 0.54 & ND & 1.31 & 0.92 \\
\hline 19:0 & ND & ND & 0.16 & 0.16 \\
\hline $9 t, 12 t-18: 2(\mathrm{n}-6)$ & ND & ND & 0.39 & 0.39 \\
\hline $9 c, 12 t-18: 2(\mathrm{n}-6)$ & ND & ND & 0.11 & 0.11 \\
\hline $9 t, 12 c-18: 2(\mathrm{n}-6)$ & ND & ND & 0.13 & 0.13 \\
\hline $9 c, 12 c-18: 2(\mathrm{n}-6)$ & 51.26 & 0.01 & 36.79 & 0.19 \\
\hline 20:0 & 0.50 & 0.14 & 0.37 & 0.11 \\
\hline $8 c-20: 1$ & ND & ND & 0.02 & 0.02 \\
\hline $11 c-20: 1$ & 0.25 & ND & 0.18 & 0.01 \\
\hline $9 c, 12 c, 15 c-18: 3(\mathrm{n}-3)$ & 0.88 & ND & 0.63 & ND \\
\hline 22:0 & 0.16 & ND & 0.21 & 0.10 \\
\hline 24:0 & 0.15 & ND & 0.11 & ND \\
\hline$\sum \mathrm{NI}$ & ND & ND & 2.55 & 2.55 \\
\hline Energy $(\mathrm{kJ} / \mathrm{g})$ & 16.6 & 16.6 & 16.6 & 16.6 \\
\hline
\end{tabular}

Diets were prepared according to the AIN-93G [28] except for the fatty acid sources that were based on the AIN-76 [29]. Diets: ${ }^{+}$LA: enriched with LA; ${ }^{-} \mathrm{LA}$ : deprived of LA; ${ }^{+} \mathrm{LA}+\mathrm{TFA}:{ }^{+} \mathrm{LA}$ supplemented with TFA-enriched oil; ' $\mathrm{LA}+$ TFA: ${ }^{-}$LA supplemented with TFA-enriched oil. LA: linoleic acid; TFA: trans fatty acids; ND: not detected; NI: other nonidentified fatty acids

${ }^{\mathrm{a}}$ Grams per $\mathrm{Kg}$ diet

${ }^{\mathrm{b}}$ Weight percentage of total fatty acids diets was the type of lipid. Each diet was freshly prepared every 3 days throughout the experimental period.

\section{Experimental protocol}

Throughout the entire dietary treatment period, the rats were weighed and the food intake was recorded three times per week. Food was removed at 6:00 AM on the morning of day 60 , and the rats were anesthetized ( $1 \mathrm{mg}$ of acepromazine $+100 \mathrm{mg}$ of ketamine $/ \mathrm{kg}$ of body weight) after $4 \mathrm{~h}$ (at 10:00 AM). Blood and soleus and gastrocnemius muscles were extracted for the assays. Soleus muscles were used to measure glucose uptake and metabolism in response to insulin and/or palmitate due to its high metabolic and oxidative capacity.

\section{Fatty acid composition in serum, muscle, and dietary lipids}

Total lipids in the serum and gastrocnemius muscle $(n=6$ per group) were extracted, using the method described by Bligh and Dyer [30]. The FA in the serum, muscle, and dietary lipids were analyzed by gas chromatography. The FA methyl esters (FAME) were obtained from the basecatalyzed methanolysis of the glycerides ( $\mathrm{KOH}$ in methanol), after dissolving the lipid extract in high-performance liquid chromatography quality hexane [31]. The total FA profile was recorded by analyzing the FAME on a gas-liquid chromatograph (Shimadzu 2014, Kyoto, Japan), with an autoinjector (AOC-20i) Split/Splitless, equipped with a flame ionization detector and a CP Sil 88 fused silica capillary column $(100 \mathrm{~m} \times 0.25 \mathrm{~mm} \times 0.2 \mu \mathrm{m}$, film thickness; Varian, Lake Forest, CA, USA), according to the American Oil Chemists' Society Official Method [32]. The FAME were identified by comparing their retention times to those of commercial standards. The values were expressed as a percentage of the total FAME. The detection limit for the main FAME identified ranged from 0.01 to $0.03 \%$. Similar procedure was used in our previous studies $[9,14,33]$.

\section{Biomarkers of EFA status and TFA incorporation}

The EFA deficiency established as a consequence of the dietary treatment in the ${ }^{-} \mathrm{LA}$ and ${ }^{-} \mathrm{LA}+\mathrm{TFA}$ groups was evaluated using the decrease in the LA and ALA levels, as well as the increase in the levels of mead acid $(5 c, 8 c, 11 c-20: 3)$, a well-known EFA deficiency biomarker, and the triene/tetraene $(5 c, 8 c, 11 c-20: 3 / 5 c, 8 c, 11 c, 1$ $4 c-20: 4)$ ratio in the serum and muscle. The incorporation of TFA isomers in the ${ }^{+} \mathrm{LA}+\mathrm{TFA}$ and ${ }^{-} \mathrm{LA}+\mathrm{TFA}$ groups was evaluated based on the individual isomer levels in the serum and muscle. 


\section{Estimation of key product/precursor ratios involved in the FA metabolism}

To estimate the index of $\Delta 9-, \Delta 6-$, and $\Delta 5$-desaturase activities, the product/precursor ratios were calculated in serum and muscle [34]. Thus, $9 c-16: 1 / 16: 0$ and $9 c$ 18:1/18:0 ratios were considered to assess the index of $\Delta 9$-desaturase activity. Moreover, the $6 c, 9 c, 12 c$ 18:3/9c,12c-18:2 (GLA/LA, where GLA $=\gamma$-linolenic acid) and $5 c, 8 c, 11 c, 14 c-20: 4 / 8 c, 11 c, 14 c-20: 3$ (AA/DGLA, where DGLA $=$ dihomo- $\gamma$-linolenic acid) ratios were used to evaluate the index of $\Delta 6$ - and $\Delta 5$-desaturase activities. In addition, the relative conversion rates of LC-PUFA of $\mathrm{n}-6$ and $\mathrm{n}-3$ series were calculated using the $5 c, 8 c, 11 c, 14 c$ 20:4/9c, 12c-18:2 (AA/LA, where $\mathrm{AA}=$ arachidonic acid) and 4c,7c,10c,13c,16c,19c-22:6/9c,12c,15c-18:3 (DHA/ALA, where DHA = docosahexaenoic acid) ratios, respectively.

\section{Serum glucose levels}

The serum glucose levels ( $n=6$ per group) were determined by spectrophotometry, using a commercially available kit (Sociedad de Bioquímicos, Santa Fe, Argentina).

\section{Glucose metabolism studies}

\section{Isolation and incubation of strips of soleus muscle}

The soleus muscles ( $n=4$ per group) were isolated and incubated as previously described [35-37]. Soleus muscle strips weighing $25-35 \mathrm{mg}$ were attached to stainless steel clips, to maintain resting tension, and preincubated for $4 \mathrm{~h}$ at $35^{\circ} \mathrm{C}$ in Krebs-Ringer buffer at $\mathrm{pH} 7.4$ (containing $5 \mathrm{mM}$ glucose and $1 \% \mathrm{wt} / \mathrm{vol}$ bovine serum albumin), previously gassed with $95 \% \mathrm{O}_{2} / 5 \% \mathrm{CO}_{2}$ for $30 \mathrm{~min}$, in the presence or absence of $400 \mu \mathrm{M}$ palmitate. This protocol has been used to induce muscle insulin resistance in vitro using saturated fatty acid [14, 38]. Afterwards, soleus muscle strips were transferred to other vials containing the same buffer supplemented with $0.2 \mu \mathrm{Ci} / \mathrm{mL}\left[\mathrm{U}-{ }^{14} \mathrm{C}\right] \mathrm{D}$-glucose and $0.2 \mu \mathrm{Ci} / \mathrm{mL} 2$-deoxy-[2,6- $\left.{ }^{3} \mathrm{H}\right] \mathrm{D}$-glucose. Muscles were then incubated for one hour in the absence or presence of $7 \mathrm{nM}$ insulin. Consequently, four experimental conditions were established for each group: basal (B), in the presence of insulin $(+\mathrm{I})$, in the presence of palmitate $(+\mathrm{P})$, or in the presence of insulin + palmitate $(+\mathrm{I}+\mathrm{P})$.

Glucose uptake, incorporation and oxidation, and glycogen synthesis measurements

The $\left[\mathrm{U}_{-}{ }^{14} \mathrm{C}\right] \mathrm{D}$-glucose oxidation was estimated based on ${ }^{14} \mathrm{CO}_{2}$ production, according to Leighton et al. [39] and reported in our previous studies [36]. A microtube containing a filter paper embedded in $2 \mathrm{~N} \mathrm{NaOH}$ aqueous solution was inserted into the vials to absorb the ${ }^{14} \mathrm{CO}_{2}$ released during muscle incubation. The radioactivity of ${ }^{14} \mathrm{CO}_{2}$ in the filter paper was quantified. To determine the 2-deoxy-[2,6$\left.{ }^{3} \mathrm{H}\right] \mathrm{D}$-glucose uptake, $\left[\mathrm{U}-{ }^{14} \mathrm{C}\right] \mathrm{D}$-glucose incorporation, and ${ }^{14} \mathrm{C}$-glycogen synthesis, the muscles were digested with $1 \mathrm{~N} \mathrm{KOH}$ aqueous solution at $70^{\circ} \mathrm{C}$ for $20 \mathrm{~min}$ at the end of the incubation period [37, 40]. An aliquot of the muscle homogenate was used to quantify the incorporation of ${ }^{3} \mathrm{H}$ and ${ }^{14} \mathrm{C}$ radioactivity, in order to determine the 2-deoxy-[2,6- $\left.{ }^{3} \mathrm{H}\right] \mathrm{D}$-glucose uptake and $\left[\mathrm{U}-{ }^{14} \mathrm{C}\right] \mathrm{D}$-glucose incorporation, respectively. Another aliquot of the muscle homogenate was used to measure the ${ }^{14} \mathrm{C}$-glycogen synthesis. The total muscle glycogen was precipitated using a saturated solution of $\mathrm{Na}_{2} \mathrm{SO}_{4}$ and nonlabeled glycogen solution in a cold ethanolic solution $\left(-20^{\circ} \mathrm{C}\right)$. The samples were centrifuged at $400 \times g$, and total glycogen was resuspended in distilled water. The ${ }^{14} \mathrm{C}$ radioactivity was then quantified to determine the ${ }^{14} \mathrm{C}$-glycogen synthesis [40].

\section{Statistical analyses}

The results are expressed as means \pm SEM of 4-6 animals per group. Significant differences between mean values were established by Two-Way Analysis of Variance (ANOVA; $2 \times 2$ ), using the LA levels and TFA supplementation as independent variables. All post hoc multiple comparisons were performed using Scheffe's critical range test. To compare the effect of insulin and palmitate in each group, significant differences between means were established using unpaired Student's $t$ test. Differences were considered statistically significant at $p<0.05$ using IBM SPSS statistics (version 17.0 for windows) [41].

\section{Results}

\section{Physiological status, nutritional parameters, and FA composition}

All animals appeared healthy without any undesirable manifestation due to EFA deficiency or pathological signs due to the different treatments. The average daily food intake did not differ among the groups (Table 2). Nevertheless, there was an increase of the body weight gain in the two groups supplemented with TFA. In the ANOVA analysis, TFA decreased the glucose levels, reaching significant difference in ${ }^{-} \mathrm{LA}+\mathrm{TFA}$ versus ${ }^{+} \mathrm{LA}$ group.

The serum and muscle FA composition was significantly different among the groups. LA deprivation, but not TFA supplementation, significantly increased serum mead acid levels, a FA derived from the exacerbated synthesis 
Table 2 Effect of TFA on food intake, body weight gain, and serum glucose levels in rats fed LA-enriched or LA-deprived diets

\begin{tabular}{|c|c|c|c|c|c|c|c|}
\hline & \multicolumn{4}{|c|}{ Experimental groups } & \multicolumn{3}{|c|}{ ANOVA } \\
\hline & ${ }^{+} \mathrm{LA}$ & ${ }^{-} \mathrm{LA}$ & ${ }^{+} \mathrm{LA}+\mathrm{TFA}$ & ${ }^{-} \mathrm{LA}+\mathrm{TFA}$ & LA & TFA & $\begin{array}{l}\text { LA } \times \\
\text { TFA }\end{array}$ \\
\hline Food intake (g per day) & $17.71 \pm 0.50$ & $18.70 \pm 0.35$ & $17.76 \pm 0.48$ & $18.74 \pm 1.12$ & NS & NS & NS \\
\hline Body weight gained $(\mathrm{g})$ & $209 \pm 7^{a}$ & $226 \pm 7^{\mathrm{ab}}$ & $251 \pm 7^{\mathrm{bc}}$ & $268 \pm 10^{\mathrm{c}}$ & NS & S & NS \\
\hline Serum glucose levels (g/L) & $1.32 \pm 0.09^{\mathrm{a}}$ & $1.21 \pm 0.05^{\mathrm{ab}}$ & $1.21 \pm 0.06^{\mathrm{ab}}$ & $0.95 \pm 0.09^{b}$ & NS & $\mathrm{S}$ & NS \\
\hline
\end{tabular}

Data are means \pm SEM, $n=6$ per group. Statistical differences were established by two-way ANOVA $(2 \times 2)$ followed by Scheffe's test. For the ANOVA test, S indicates $p<0.05$ and NS $p>0.05$. For Scheffe's test, values in the same row with different superscript letters are significantly different $(p<0.05)$

Experimental groups: ${ }^{+} \mathrm{LA}$ : enriched with LA; ${ }^{-} \mathrm{LA}$ : deprived of LA; ${ }^{+} \mathrm{LA}+\mathrm{TFA}:{ }^{+} \mathrm{LA}$ supplemented with TFA-enriched oil; ${ }^{-} \mathrm{LA}+\mathrm{TFA}:{ }^{-} \mathrm{LA}$ supplemented with TFA-enriched oil. LA linoleic acid, TFA trans fatty acid

of LC-PUFA of n-9 FA in EFA deficiency, and the triene/ tetraene ratio. A similar behavior was observed in the muscle. Total saturated FA (SFA) and cis-monounsaturated FA (MUFA) levels were significantly higher in serum and muscle of both ${ }^{-}$LA and ${ }^{-}$LA + TFA groups as a result of the FA composition changes in LA-deficient diets. On the other hand, polyunsaturated FA (PUFA) levels were significantly reduced in both LA-deprived groups, leading to a lower $\sum$ PUFA/ $\sum$ SFA ratio in the LA-deprived groups. In serum and muscle, the AA/LA ratio, reflecting the relative conversion rate of LA to AA, did not differ among the groups. Nevertheless, ALA conversion to DHA (DHA/ALA ratio) was increased by TFA supplementation in the LA-deprived group. The $\Delta 9$-desaturase index, expressed by the $9 c$ 16:1/16:0 and $9 c-18: 1 / 18: 0$ ratios, and the $\Delta 6$-desaturase index, expressed by the GLA/LA ratio, were increased in the LA-deprived groups, regardless of the TFA supplementation. On the contrary, the $\Delta 5$-desaturase index (AA/ DGLA) was reduced by LA deprivation. All dietary trans18:1 FA were incorporated into the lipids of serum and muscle. Both TFA-supplemented groups had equivalent levels of total and individual trans-18:1. Of the trans-18:1 isomers measured, 9t-18:1 had the highest level. The level of $9 c, 11 t-18: 2$ produced by bioconversion from $11 t-18: 1$, was higher in skeletal muscle than in serum, and in muscle their levels were not affected by the LA status (Tables 3, 4).

\section{Glucose metabolism}

Glucose uptake, incorporation, and oxidation, as well as glycogen synthesis in the soleus muscle, either under basal conditions or in the presence of insulin, palmitate, and insulin plus palmitate, were measured (Table 5). Under basal conditions, glucose uptake was increased by LA deprivation and TFA supplementation ( ${ }^{-} \mathrm{LA}+$ TFA group) compared with the ${ }^{+}$LA group. Regardless of the dietary composition, insulin increased glucose uptake when compared with basal conditions. Nevertheless, compared with the ${ }^{+} \mathrm{LA}$, the insulin response (Fig. 1a) was less pronounced in both TFA-supplemented groups. The palmitate treatment did not inhibit basal glucose uptake. Palmitate treatment in the presence of insulin $(+\mathrm{I}+\mathrm{P})$ partially, but significantly, inhibited the insulin-stimulated glucose uptake in the ${ }^{+} \mathrm{LA}$, ${ }^{-} \mathrm{LA}$, and ${ }^{-} \mathrm{LA}+\mathrm{TFA}$ groups, but not in the ${ }^{+} \mathrm{LA}+\mathrm{TFA}$ group. The relative response in relation to its basal value (Fig. 1c) was decreased in the ${ }^{-} \mathrm{LA}$ and ${ }^{-} \mathrm{LA}+\mathrm{TFA}$ groups compared with the ${ }^{+}$LA group.

The glucose incorporation under basal conditions did not have differences in the individual comparisons among the experimental groups. Nevertheless, in the $2 \times 2$ ANOVA analyses, the TFA-supplemented groups exhibited improved glucose incorporation. Insulin stimulation increased glucose incorporation in all groups. Similar to the effect on glucose uptake, glucose incorporation stimulated by insulin (Fig. 2a) was decreased in the TFA-supplemented $\left({ }^{+} \mathrm{LA}+\mathrm{TFA}\right.$ and $\left.{ }^{-} \mathrm{LA}+\mathrm{TFA}\right)$ groups as well as in the ${ }^{-}$LA group, compared with the control $\left({ }^{+}\right.$LA group). The addition of palmitate did not inhibit glucose incorporation under basal conditions. Nevertheless, the palmitate in the presence of insulin $(+\mathrm{I}+\mathrm{P})$ partially inhibited the effect of the hormone $(+\mathrm{I})$ on the glucose incorporation in the ${ }^{+} \mathrm{LA},{ }^{-} \mathrm{LA}$, and ${ }^{-} \mathrm{LA}+\mathrm{TFA}$ groups but not in the ${ }^{+}$LA + TFA group. However, the glucose incorporation did not differ among the experimental groups in the palmitate treatment in the presence of insulin $(+\mathrm{I}+\mathrm{P})$ or the relative response (Fig. 2c).

Glucose oxidation under basal conditions was increased by TFA supplementation, reaching statistical significance in the ${ }^{-} \mathrm{LA}+\mathrm{TFA}$ group compared with the ${ }^{+} \mathrm{LA}$ group. Insulin stimulation increased glucose oxidation when compared with the basal condition in the ${ }^{+}$LA and ${ }^{-}$LA + TFA groups. The insulin response (Fig. 3a) was lowered in the ${ }^{-}$LA and ${ }^{+} \mathrm{LA}+\mathrm{TFA}$ groups compared with the +LA group. The treatment with palmitate reduced glucose oxidation only in the ${ }^{+} \mathrm{LA}+$ TFA group when compared with the basal value and among the experimental groups. The fatty acid in the 
Table 3 Effect of TFA supplementation on serum fatty acid levels in rats fed LA-enriched or LA-deprived diets

\begin{tabular}{|c|c|c|c|c|c|c|c|}
\hline \multirow[t]{2}{*}{ Fatty acids* } & \multicolumn{4}{|c|}{ Experimental groups } & \multicolumn{3}{|c|}{ ANOVA } \\
\hline & ${ }^{+} \mathrm{LA}$ & ${ }^{-} \mathrm{LA}$ & ${ }^{+} \mathrm{LA}+\mathrm{TFA}$ & ${ }^{-} \mathrm{LA}+\mathrm{TFA}$ & LA & TFA & $\begin{array}{l}\text { LA } \times \\
\text { TFA }\end{array}$ \\
\hline $12: 0$ & $\mathrm{ND}^{\mathrm{a}}$ & $1.41 \pm 0.19^{\mathrm{b}}$ & $\mathrm{ND}^{\mathrm{a}}$ & $0.68 \pm 0.22^{\mathrm{c}}$ & $\mathrm{S}$ & $\mathrm{S}$ & $S$ \\
\hline $14: 0$ & $0.31 \pm 0.03^{\mathrm{a}}$ & $2.35 \pm 0.28^{\mathrm{b}}$ & $0.40 \pm 0.02^{\mathrm{a}}$ & $1.34 \pm 0.18^{\mathrm{c}}$ & $\mathrm{S}$ & $\mathrm{S}$ & $S$ \\
\hline $16: 0$ & $20.06 \pm 0.31$ & $20.66 \pm 0.96$ & $18.77 \pm 0.44$ & $19.40 \pm 0.28$ & NS & $\mathrm{S}$ & NS \\
\hline $9 c-16: 1$ & $0.90 \pm 0.22^{\mathrm{a}}$ & $4.37 \pm 0.13^{b}$ & $1.52 \pm 0.04^{\mathrm{c}}$ & $3.67 \pm 0.58^{b}$ & $\mathrm{~S}$ & NS & NS \\
\hline 18:0 & $15.09 \pm 1.16$ & $16.95 \pm 1.35$ & $16.89 \pm 0.81$ & $18.56 \pm 1.31$ & NS & NS & NS \\
\hline$(6-8) t-18: 1$ & $\mathrm{ND}^{\mathrm{a}}$ & $\mathrm{ND}^{\mathrm{a}}$ & $0.39 \pm 0.01^{\mathrm{b}}$ & $0.29 \pm 0.02^{\mathrm{c}}$ & NS & $\mathrm{S}$ & $\mathrm{S}$ \\
\hline $9 t-18: 1(\mathrm{n}-9)$ & $\mathrm{ND}^{\mathrm{a}}$ & $\mathrm{ND}^{\mathrm{a}}$ & $0.75 \pm 0.10^{\mathrm{b}}$ & $0.80 \pm 0.05^{\mathrm{b}}$ & NS & $\mathrm{S}$ & NS \\
\hline $10 t-18: 1$ & $\mathrm{ND}^{\mathrm{a}}$ & $\mathrm{ND}^{\mathrm{a}}$ & $0.29 \pm 0.04^{\mathrm{b}}$ & $0.36 \pm 0.05^{\mathrm{b}}$ & NS & $\mathrm{S}$ & NS \\
\hline $11 t-18: 1$ & $\mathrm{ND}^{\mathrm{a}}$ & $\mathrm{ND}^{\mathrm{a}}$ & $0.71 \pm 0.08^{b}$ & $0.52 \pm 0.07^{\mathrm{b}}$ & NS & $\mathrm{S}$ & NS \\
\hline $12 t-18: 1(\mathrm{n}-6)$ & $\mathrm{ND}^{\mathrm{a}}$ & $\mathrm{ND}^{\mathrm{a}}$ & $0.77 \pm 0.03^{\mathrm{b}}$ & $0.61 \pm 0.07^{b}$ & NS & $\mathrm{S}$ & NS \\
\hline $9 c-18: 1(\mathrm{n}-9)$ & $9.65 \pm 0.80^{\mathrm{a}}$ & $17.03 \pm 1.52^{b}$ & $9.73 \pm 0.46^{\mathrm{a}}$ & $14.90 \pm 0.96^{\mathrm{b}}$ & $\mathrm{S}$ & NS & NS \\
\hline $11 c-18: 1$ & $2.66 \pm 0.17^{\mathrm{a}}$ & $5.14 \pm 0.21^{\mathrm{b}}$ & $2.41 \pm 0.24^{\mathrm{a}}$ & $4.83 \pm 0.18^{\mathrm{b}}$ & $\mathrm{S}$ & NS & NS \\
\hline $9 c, 12 c-18: 2(\mathrm{n}-6)$ & $20.20 \pm 0.59^{\mathrm{a}}$ & $7.89 \pm 0.53^{b}$ & $16.16 \pm 0.53^{\mathrm{c}}$ & $8.47 \pm 0.34^{b}$ & $\mathrm{~S}$ & $\mathrm{~S}$ & $\mathrm{~S}$ \\
\hline $6 c, 9 c, 12 c-18: 3(\mathrm{n}-6)$ & $0.06 \pm 0.02^{\mathrm{a}}$ & $0.26 \pm 0.02^{\mathrm{b}}$ & $0.12 \pm 0.00^{\mathrm{c}}$ & $0.00 \pm 0.00^{\mathrm{d}}$ & $\mathrm{S}$ & $\mathrm{S}$ & $S$ \\
\hline $11 c-20: 1(\mathrm{n}-9)$ & $0.11 \pm 0.01$ & $0.16 \pm 0.03$ & $0.18 \pm 0.01$ & $0.11 \pm 0.01$ & NS & NS & $\mathrm{S}$ \\
\hline $9 c, 12 c, 15 c-18: 3(\mathrm{n}-3)$ & $0.22 \pm 0.01^{\mathrm{a}}$ & $0.20 \pm 0.01^{\mathrm{a}}$ & $0.19 \pm 0.01^{\mathrm{a}}$ & $0.14 \pm 0.01^{b}$ & $\mathrm{~S}$ & $\mathrm{~S}$ & NS \\
\hline $9 c, 11 t$-CLA & $\mathrm{ND}^{\mathrm{a}}$ & $\mathrm{ND}^{\mathrm{a}}$ & $\mathrm{ND}^{\mathrm{a}}$ & $0.22 \pm 0.03^{\mathrm{b}}$ & $\mathrm{S}$ & $\mathrm{S}$ & $\mathrm{S}$ \\
\hline $11 c, 14 c-20: 2(\mathrm{n}-6)$ & $0.45 \pm 0.03^{\mathrm{a}}$ & $0.16 \pm 0.04^{\mathrm{b}}$ & $0.56 \pm 0.05^{\mathrm{a}}$ & $\mathrm{ND}^{\mathrm{b}}$ & $\mathrm{S}$ & NS & $\mathrm{S}$ \\
\hline $22: 0$ & $\mathrm{ND}^{\mathrm{a}}$ & $3.60 \pm 0.17^{\mathrm{b}}$ & $0.34 \pm 0.02^{\mathrm{a}}$ & $3.93 \pm 0.41^{\mathrm{b}}$ & $\mathrm{S}$ & NS & NS \\
\hline $8 c, 11 c-20: 2(\mathrm{n}-9)$ & $\mathrm{ND}^{\mathrm{a}}$ & $0.41 \pm 0.03^{b}$ & $\mathrm{ND}^{\mathrm{a}}$ & $0.57 \pm 0.09^{\mathrm{b}}$ & $\mathrm{S}$ & NS & NS \\
\hline $5 c, 8 c, 11 c-20: 3(\mathrm{n}-9)$ & $\mathrm{ND}^{\mathrm{a}}$ & $0.36 \pm 0.05^{\mathrm{b}}$ & $\mathrm{ND}^{\mathrm{a}}$ & $0.29 \pm 0.04^{\mathrm{b}}$ & $\mathrm{S}$ & NS & NS \\
\hline $8 c, 11 c, 14 c-20: 3(\mathrm{n}-6)$ & $0.46 \pm 0.04^{\mathrm{ac}}$ & $1.12 \pm 0.07^{\mathrm{b}}$ & $0.29 \pm 0.04^{\mathrm{c}}$ & $1.35 \pm 0.09^{\mathrm{b}}$ & $\mathrm{S}$ & NS & $\mathrm{S}$ \\
\hline $11 c, 14 c, 17 c-20: 3(\mathrm{n}-3)$ & $\mathrm{ND}^{\mathrm{a}}$ & $0.35 \pm 0.08^{\mathrm{b}}$ & $\mathrm{ND}^{\mathrm{a}}$ & $0.78 \pm 0.13^{\mathrm{c}}$ & $\mathrm{S}$ & $\mathrm{S}$ & $\mathrm{S}$ \\
\hline $5 c, 8 c, 11 c, 14 c-20: 4(\mathrm{n}-6)$ & $24.95 \pm 0.76^{\mathrm{a}}$ & $9.50 \pm 0.56^{\mathrm{b}}$ & $24.51 \pm 0.92^{\mathrm{a}}$ & $10.19 \pm 0.39^{\mathrm{b}}$ & $\mathrm{S}$ & NS & NS \\
\hline $4 c, 7 c, 10 c, 13 c, 16 c, 19 c-22: 6(\mathrm{n}-3)$ & $1.96 \pm 0.18$ & $1.70 \pm 0.07$ & $1.62 \pm 0.10$ & $2.39 \pm 0.40$ & NS & NS & $\mathrm{S}$ \\
\hline$\sum \mathrm{NI}$ & $1.97 \pm 0.15$ & $1.43 \pm 0.11$ & $3.05 \pm 0.03$ & $2.59 \pm 0.23$ & $\mathrm{~S}$ & $\mathrm{~S}$ & NS \\
\hline$\sum \mathrm{SFA}$ & $35.46 \pm 1.22^{\mathrm{a}}$ & $44.97 \pm 1.10^{\mathrm{b}}$ & $36.40 \pm 0.66^{\mathrm{a}}$ & $43.91 \pm 1.25^{\mathrm{b}}$ & $\mathrm{S}$ & NS & NS \\
\hline$\sum$ MUFA & $13.32 \pm 1.01^{\mathrm{ac}}$ & $26.70 \pm 1.78^{b}$ & $16.75 \pm 1.10^{\mathrm{c}}$ & $26.09 \pm 1.44^{\mathrm{b}}$ & $\mathrm{S}$ & NS & NS \\
\hline$\sum$ PUFA & $48.30 \pm 0.93^{\mathrm{a}}$ & $21.62 \pm 0.35^{\mathrm{b}}$ & $43.52 \pm 1.26^{\mathrm{c}}$ & $24.56 \pm 0.31^{\mathrm{b}}$ & $\mathrm{S}$ & NS & $S$ \\
\hline$\sum \mathrm{TFA}$ & $\mathrm{ND}^{\mathrm{a}}$ & $\mathrm{ND}^{\mathrm{a}}$ & $2.98 \pm 0.27^{b}$ & $2.96 \pm 0.17^{b}$ & NS & $\mathrm{S}$ & NS \\
\hline Triene/Tetraene & $\mathrm{ND}^{\mathrm{a}}$ & $0.04 \pm 0.00^{\mathrm{b}}$ & $\mathrm{ND}^{\mathrm{a}}$ & $0.03 \pm 0.00^{\mathrm{b}}$ & $\mathrm{S}$ & NS & NS \\
\hline $9 c-16: 1 / 16: 0$ & $0.05 \pm 0.01^{\mathrm{a}}$ & $0.21 \pm 0.01^{\mathrm{b}}$ & $0.08 \pm 0.00^{\mathrm{a}}$ & $0.19 \pm 0.03^{b}$ & $\mathrm{~S}$ & NS & NS \\
\hline $9 c-18: 1 / 18: 0$ & $0.67 \pm 0.10$ & $1.05 \pm 0.15$ & $0.58 \pm 0.05$ & $0.84 \pm 0.12$ & $\mathrm{~S}$ & NS & NS \\
\hline AA/DGLA & $54.91 \pm 2.89^{\mathrm{a}}$ & $8.52 \pm 0.09^{b}$ & $89.43 \pm 11.25^{\mathrm{c}}$ & $7.72 \pm 0.76^{\mathrm{b}}$ & $\mathrm{S}$ & $\mathrm{S}$ & $\mathrm{S}$ \\
\hline GLA/LA & $0.003 \pm 0.001^{\mathrm{a}}$ & $0.034 \pm 0.004^{b}$ & $0.007 \pm 0.000^{\mathrm{a}}$ & $0.000 \pm 0.000^{\mathrm{a}}$ & $\mathrm{S}$ & $\mathrm{S}$ & $\mathrm{S}$ \\
\hline AA/LA & $1.24 \pm 0.05$ & $1.24 \pm 0.13$ & $1.52 \pm 0.03$ & $1.21 \pm 0.04$ & $\mathrm{~S}$ & NS & NS \\
\hline DHA/ALA & $8.94 \pm 1.18^{\mathrm{a}}$ & $8.60 \pm 0.93^{\mathrm{a}}$ & $8.59 \pm 0.16^{\mathrm{a}}$ & $17.20 \pm 2.56^{\mathrm{b}}$ & $\mathrm{S}$ & $\mathrm{S}$ & $\mathrm{S}$ \\
\hline $\mathrm{LA} / \sum \mathrm{TFA}$ & - & - & $5.66 \pm 0.64^{\mathrm{a}}$ & $3.00 \pm 0.17^{\mathrm{b}}$ & - & - & - \\
\hline$\sum$ PUFA/ $\sum$ SFA & $1.35 \pm 0.06^{\mathrm{a}}$ & $0.48 \pm 0.01^{\mathrm{b}}$ & $1.18 \pm 0.03^{\mathrm{c}}$ & $0.56 \pm 0.02^{\mathrm{b}}$ & $\mathrm{S}$ & NS & $\mathrm{S}$ \\
\hline
\end{tabular}

Data are as means \pm SEM, $n=6$ per group. Statistical differences were established by two-way ANOVA $(2 \times 2)$ followed by Scheffé's test. For the ANOVA test, $\mathrm{S}$ indicates $p<0.05$ and NS $\mathrm{p}>0.05$. For Scheffe's test, values in the same row with different superscript letters are significantly different $(p<0.05)$

* Weight percentage of total fatty acids

Experimental groups: ${ }^{+}$LA: enriched with LA; ${ }^{-} \mathrm{LA}$ : deprived of LA; ${ }^{+} \mathrm{LA}+\mathrm{TFA}:{ }^{+} \mathrm{LA}$ supplemented with TFA-enriched oil; ${ }^{-} \mathrm{LA}+\mathrm{TFA}:{ }^{-} \mathrm{LA}$ supplemented with TFA-enriched oil

$L A$ linoleic acid, TFA trans fatty acids, AA arachidonic acid, DGLA dihomo- $\gamma$-linolenic acid, GLA $\gamma$-linolenic acid, ALA $\alpha$-linolenic acid, SFA saturated fatty acids, MUFA monounsaturated fatty acids, PUFA polyunsaturated fatty acids, ND not detected, NI other nonidentified fatty acids 
Table 4 Effect of TFA supplementation on muscle FA composition in rats fed LA-enriched or LA-deprived diets

\begin{tabular}{|c|c|c|c|c|c|c|c|}
\hline \multirow[t]{2}{*}{ Fatty acids* } & \multicolumn{4}{|c|}{ Experimental groups } & \multicolumn{3}{|c|}{ ANOVA } \\
\hline & ${ }^{+} \mathrm{LA}$ & ${ }^{-} \mathrm{LA}$ & ${ }^{+} \mathrm{LA}+\mathrm{TFA}$ & ${ }^{-} \mathrm{LA}+\mathrm{TFA}$ & LA & TFA & $\begin{array}{l}\text { LA } \times \\
\text { TFA }\end{array}$ \\
\hline $12: 0$ & $0.06 \pm 0.01^{\mathrm{a}}$ & $5.54 \pm 0.08^{\mathrm{b}}$ & $0.10 \pm 0.03^{\mathrm{a}}$ & $2.73 \pm 0.56^{\mathrm{ab}}$ & S & NS & NS \\
\hline $14: 0$ & $0.74 \pm 0.05^{\mathrm{a}}$ & $4.52 \pm 0.90^{\mathrm{b}}$ & $0.88 \pm 0.08^{\mathrm{a}}$ & $2.97 \pm 0.40^{\mathrm{ab}}$ & S & NS & NS \\
\hline $16: 0$ & $23.37 \pm 0.25^{\mathrm{a}}$ & $26.20 \pm 0.60^{\mathrm{b}}$ & $23.12 \pm 0.55^{\mathrm{a}}$ & $26.17 \pm 0.33^{\mathrm{b}}$ & $S$ & NS & NS \\
\hline $9 c-16: 1$ & $2.86 \pm 0.34^{\mathrm{a}}$ & $9.60 \pm 1.17^{b}$ & $4.34 \pm 0.54^{\mathrm{ac}}$ & $7.11 \pm 0.43^{\mathrm{bc}}$ & S & NS & $\mathrm{S}$ \\
\hline 18:0 & $8.64 \pm 0.19$ & $6.62 \pm 1.45$ & $6.80 \pm 0.41$ & $7.80 \pm 0.53$ & NS & NS & NS \\
\hline$(6-8) t-18: 1$ & $\mathrm{ND}^{\mathrm{a}}$ & $\mathrm{ND}^{\mathrm{a}}$ & $0.25 \pm 0.01^{\mathrm{b}}$ & $0.26 \pm 0.02^{\mathrm{b}}$ & NS & S & NS \\
\hline $9 t-18: 1(\mathrm{n}-9)$ & $\mathrm{ND}^{\mathrm{a}}$ & $\mathrm{ND}^{\mathrm{a}}$ & $0.46 \pm 0.03^{b}$ & $0.58 \pm 0.06^{\mathrm{b}}$ & NS & $\mathrm{S}$ & NS \\
\hline $10 t-18: 1$ & $\mathrm{ND}^{\mathrm{a}}$ & $\mathrm{ND}^{\mathrm{a}}$ & $0.25 \pm 0.02^{\mathrm{b}}$ & $0.22 \pm 0.02^{\mathrm{b}}$ & NS & $\mathrm{S}$ & NS \\
\hline $11 t-18: 1$ & $\mathrm{ND}^{\mathrm{a}}$ & $\mathrm{ND}^{\mathrm{a}}$ & $0.33 \pm 0.01^{\mathrm{b}}$ & $0.26 \pm 0.01^{\mathrm{c}}$ & NS & $\mathrm{S}$ & $\mathrm{S}$ \\
\hline $12 t-18: 1(\mathrm{n}-6)$ & $\mathrm{ND}^{\mathrm{a}}$ & $\mathrm{ND}^{\mathrm{a}}$ & $0.26 \pm 0.01^{b}$ & $0.23 \pm 0.03^{b}$ & NS & $\mathrm{S}$ & NS \\
\hline $9 c-18: 1(n-9)$ & $12.78 \pm 0.60^{\mathrm{a}}$ & $28.32 \pm 1.84^{\mathrm{b}}$ & $14.96 \pm 1.29^{\mathrm{a}}$ & $18.13 \pm 1.63^{\mathrm{a}}$ & $S$ & $\mathrm{~S}$ & $\mathrm{~S}$ \\
\hline $11 c-18: 1$ & $4.19 \pm 0.38^{\mathrm{a}}$ & $0.06 \pm 0.01^{\mathrm{b}}$ & $5.46 \pm 0.41^{\mathrm{a}}$ & $5.88 \pm 0.42^{\mathrm{a}}$ & $S$ & $\mathrm{~S}$ & $\mathrm{~S}$ \\
\hline $9 c, 12 c-18: 2(\mathrm{n}-6)$ & $21.36 \pm 1.34^{\mathrm{a}}$ & $6.72 \pm 0.52^{b}$ & $20.71 \pm 1.85^{\mathrm{a}}$ & $7.48 \pm 0.42^{\mathrm{b}}$ & $S$ & NS & NS \\
\hline $6 c, 9 c, 12 c-18: 3(\mathrm{n}-6)$ & $0.04 \pm 0.01$ & $0.03 \pm 0.01$ & $0.02 \pm 0.00$ & $0.03 \pm 0.00$ & NS & NS & NS \\
\hline $11 c-20: 1(\mathrm{n}-9)$ & $0.06 \pm 0.00^{\mathrm{a}}$ & $0.04 \pm 0.00^{\mathrm{ab}}$ & $0.06 \pm 0.01^{\mathrm{a}}$ & $0.02 \pm 0.00^{\mathrm{b}}$ & S & NS & NS \\
\hline $9 c, 12 c, 15 c-18: 3(\mathrm{n}-3)$ & $0.16 \pm 0.02^{\mathrm{a}}$ & $0.06 \pm 0.02^{b}$ & $0.14 \pm 0.02^{\mathrm{a}}$ & $0.07 \pm 0.01^{\mathrm{b}}$ & $S$ & NS & NS \\
\hline $9 c, 11 t$-CLA & $\mathrm{ND}^{\mathrm{a}}$ & $\mathrm{ND}^{\mathrm{a}}$ & $0.37 \pm 0.05^{\mathrm{b}}$ & $0.25 \pm 0.03^{b}$ & NS & S & NS \\
\hline $11 c, 14 c-20: 2(n-6)$ & $0.20 \pm 0.01^{\mathrm{a}}$ & $0.02 \pm 0.00^{\mathrm{b}}$ & $0.13 \pm 0.00^{c}$ & $0.04 \pm 0.01^{\mathrm{b}}$ & $S$ & $S$ & $\mathrm{~S}$ \\
\hline $22: 0$ & $0.01 \pm 0.00^{\mathrm{a}}$ & $\mathrm{ND}^{\mathrm{a}}$ & $0.01 \pm 0.01^{\mathrm{a}}$ & $0.06 \pm 0.02^{\mathrm{b}}$ & NS & $\mathrm{S}$ & $\mathrm{S}$ \\
\hline $8 c, 11 c-20: 2(\mathrm{n}-9)$ & $0.06 \pm 0.02$ & $0.11 \pm 0.03$ & $0.07 \pm 0.01$ & $0.17 \pm 0.03$ & $S$ & NS & NS \\
\hline $5 c, 8 c, 11 c-20: 3(\mathrm{n}-9)$ & $\mathrm{ND}^{\mathrm{a}}$ & $0.08 \pm 0.02^{\mathrm{b}}$ & $\mathrm{ND}^{\mathrm{a}}$ & $0.07 \pm 0.02^{\mathrm{b}}$ & S & NS & NS \\
\hline $8 c, 11 c, 14 c-20: 3(\mathrm{n}-6)$ & $0.38 \pm 0.02$ & $0.33 \pm 0.10$ & $0.34 \pm 0.03$ & $0.48 \pm 0.05$ & NS & NS & NS \\
\hline $11 c, 14 c, 17 c-20: 3(\mathrm{n}-3)$ & $0.06 \pm 0.01^{\mathrm{a}}$ & $0.96 \pm 0.27^{b}$ & $0.05 \pm 0.01^{\mathrm{a}}$ & $0.79 \pm 0.16^{\mathrm{b}}$ & $S$ & NS & NS \\
\hline $5 c, 8 c, 11 c, 14 c-20: 4(\mathrm{n}-6)$ & $13.08 \pm 0.91^{\mathrm{a}}$ & $4.66 \pm 1.39^{b}$ & $10.32 \pm 1.24^{\mathrm{a}}$ & $6.18 \pm 0.86^{\mathrm{b}}$ & $\mathrm{S}$ & NS & NS \\
\hline $5 c, 8 c, 11 c, 14 c, 17 c-20: 5(\mathrm{n}-3)$ & $0.01 \pm 0.00^{\mathrm{a}}$ & $0.01 \pm 0.00^{\mathrm{a}}$ & $0.01 \pm 0.00^{\mathrm{a}}$ & $0.05 \pm 0.01^{\mathrm{b}}$ & $\mathrm{S}$ & NS & NS \\
\hline $4 c, 7 c, 10 c, 13 c, 16 c, 19 c-22: 6(\mathrm{n}-3)$ & $6.34 \pm 0.46^{\mathrm{a}}$ & $2.59 \pm 0.20^{\mathrm{b}}$ & $4.85 \pm 0.41^{\mathrm{a}}$ & $5.14 \pm 1.46^{\mathrm{a}}$ & S & NS & $\mathrm{S}$ \\
\hline$\sum \mathrm{NI}$ & $6.59 \pm 0.28^{\mathrm{a}}$ & $2.20 \pm 0.42^{b}$ & $3.27 \pm 0.41^{\mathrm{b}}$ & $2.66 \pm 0.33^{\mathrm{b}}$ & $\mathrm{S}$ & $\mathrm{S}$ & $\mathrm{S}$ \\
\hline$\sum$ SFA & $33.04 \pm 0.46^{\mathrm{a}}$ & $43.16 \pm 0.03^{\mathrm{b}}$ & $31.10 \pm 0.75^{\mathrm{a}}$ & $39.89 \pm 0.91^{\mathrm{c}}$ & $S$ & $\mathrm{~S}$ & NS \\
\hline$\sum$ MFA & $21.10 \pm 1.05^{\mathrm{a}}$ & $38.72 \pm 3.00^{\mathrm{b}}$ & $28.26 \pm 1.10^{\mathrm{ac}}$ & $34.60 \pm 2.53^{b c}$ & $\mathrm{~S}$ & NS & $\mathrm{S}$ \\
\hline$\sum$ PUFA & $41.68 \pm 0.79^{\mathrm{a}}$ & $15.62 \pm 2.28^{\mathrm{b}}$ & $37.36 \pm 0.86^{\mathrm{a}}$ & $21.37 \pm 1.67^{\mathrm{b}}$ & $S$ & NS & $\mathrm{S}$ \\
\hline$\sum \mathrm{TFA}$ & $\mathrm{ND}^{\mathrm{a}}$ & $\mathrm{ND}^{\mathrm{a}}$ & $2.27 \pm 0.18^{\mathrm{b}}$ & $2.43 \pm 0.19^{b}$ & NS & $\mathrm{S}$ & NS \\
\hline Triene/Tetraene & $\mathrm{ND}^{\mathrm{a}}$ & $0.02 \pm 0.00^{\mathrm{b}}$ & $\mathrm{ND}^{\mathrm{a}}$ & $0.01 \pm 0.00^{\mathrm{b}}$ & $\mathrm{S}$ & NS & NS \\
\hline $9 c-16: 1 / 16: 0$ & $0.12 \pm 0.02^{\mathrm{a}}$ & $0.36 \pm 0.04^{\mathrm{b}}$ & $0.19 \pm 0.02^{\mathrm{ac}}$ & $0.27 \pm 0.02^{\mathrm{bc}}$ & $S$ & NS & $\mathrm{S}$ \\
\hline $9 c-18: 1 / 18: 0$ & $1.48 \pm 0.10^{\mathrm{a}}$ & $5.84 \pm 0.21^{\mathrm{b}}$ & $2.24 \pm 0.33^{\mathrm{a}}$ & $2.38 \pm 0.37^{\mathrm{a}}$ & S & $\mathrm{S}$ & $\mathrm{S}$ \\
\hline AA/DGLA & $34.66 \pm 1.66^{\mathrm{a}}$ & $13.98 \pm 0.041^{\mathrm{b}}$ & $29.99 \pm 1.73^{\mathrm{a}}$ & $12.71 \pm 0.79^{\mathrm{b}}$ & S & $\mathrm{S}$ & NS \\
\hline GLA/LA & $0.002 \pm 0.000^{\mathrm{a}}$ & $0.005 \pm 0.001^{\mathrm{b}}$ & $0.001 \pm 0.000^{\mathrm{a}}$ & $0.003 \pm 0.000^{\mathrm{ab}}$ & $S$ & NS & NS \\
\hline AA/LA & $0.62 \pm 0.08$ & $0.68 \pm 0.15$ & $0.52 \pm 0.10$ & $0.82 \pm 0.08$ & NS & NS & NS \\
\hline DHA/ALA & $42.05 \pm 8.09^{\mathrm{ab}}$ & $33.06 \pm 3.30^{\mathrm{a}}$ & $39.29 \pm 7.90^{\mathrm{a}}$ & $74.35 \pm 7.02^{\mathrm{b}}$ & NS & NS & $\mathrm{S}$ \\
\hline $\mathrm{LA} / \sum \mathrm{TFA}$ & - & - & $9.11 \pm 0.34^{\mathrm{a}}$ & $3.13 \pm 0.39^{\mathrm{b}}$ & - & - & - \\
\hline$\sum \mathrm{PUFA} / \sum \mathrm{SFA}$ & $1.26 \pm 0.03^{\mathrm{a}}$ & $0.36 \pm 0.05^{\mathrm{b}}$ & $1.20 \pm 0.05^{\mathrm{a}}$ & $0.54 \pm 0.05^{\mathrm{c}}$ & $S$ & NS & $\mathrm{S}$ \\
\hline
\end{tabular}

Data are means \pm SEM, $n=6$ per group. Statistical differences were established by two-way ANOVA $(2 \times 2)$ followed by Scheffé's test. For the ANOVA test, S indicates $p<0.05$ and NS $p>0.05$. For Scheffe's test, values in the same row with different superscript letters are significantly different $(p<0.05)$

* Weight percentage of total fatty acids

Experimental groups: ${ }^{+} \mathrm{LA}$ : enriched with LA; ${ }^{-} \mathrm{LA}$ : deprived of LA; ${ }^{+} \mathrm{LA}+\mathrm{TFA}:{ }^{+} \mathrm{LA}$ supplemented with TFA-enriched oil; ${ }^{-} \mathrm{LA}+\mathrm{TFA}:{ }^{-} \mathrm{LA}$ supplemented with TFA-enriched oil

$L A$ linoleic acid, TFA trans fatty acids, $A A$ arachidonic acid, DGLA dihomo- $\gamma$-linolenic acid, $G L A \gamma$-linolenic acid, $A L A \alpha$-linolenic acid, SFA saturated fatty acids, MUFA monounsaturated fatty acids, $P U F A$ polyunsaturated fatty acids, $N D$ not detected, $N I$ other nonidentified fatty acids 
Table 5 Effect of TFA supplementation on glucose uptake, incorporation and oxidation, and glycogen synthesis in the soleus muscle of rats fed LA-enriched or LA-deprived diets

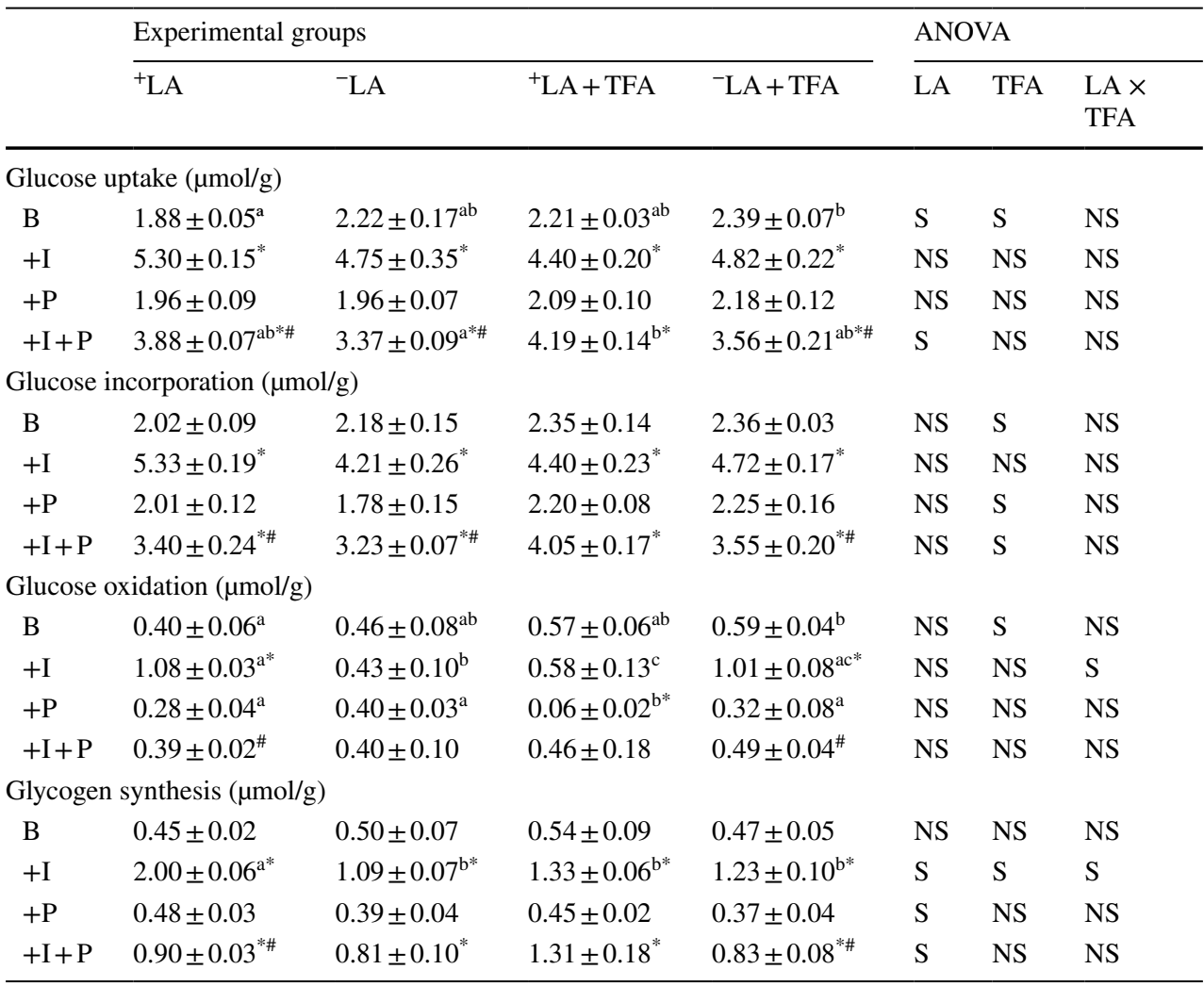

Data are means $\pm \mathrm{SEM}, n=4$ per group. Statistical differences between different groups were established by two-way ANOVA $(2 \times 2)$, followed by Scheffe's test. For the ANOVA test, S indicates $p<0.05$ and NS $p>0.05$. For the Scheffe's test, values in the same row with different superscript letters are significantly different $(p<0.05)$. Statistical differences between different experimental conditions in each group were established by Student's t test and identified at $p<0.05$ by $*$ between $+\mathrm{I}$ and $\mathrm{B},+\mathrm{P}$ and $\mathrm{B}$, and $+\mathrm{I}+\mathrm{P}$ and $\mathrm{B}$, and by \# between $+\mathrm{I}+\mathrm{P}$ and $+\mathrm{I}$

Experimental groups: ${ }^{+} \mathrm{LA}$ : enriched with LA; ${ }^{-} \mathrm{LA}$ : deprived of LA; ${ }^{+} \mathrm{LA}+\mathrm{TFA}:{ }^{+} \mathrm{LA}$ supplemented with TFA-enriched oil; ' $\mathrm{LA}+\mathrm{TFA}:{ }^{-}$LA supplemented with TFA-enriched oil

$L A$ linoleic acid, TFA trans fatty acids, $B$ basal; $+I$ with the addition of insulin, $+P$ with the addition of palmitate
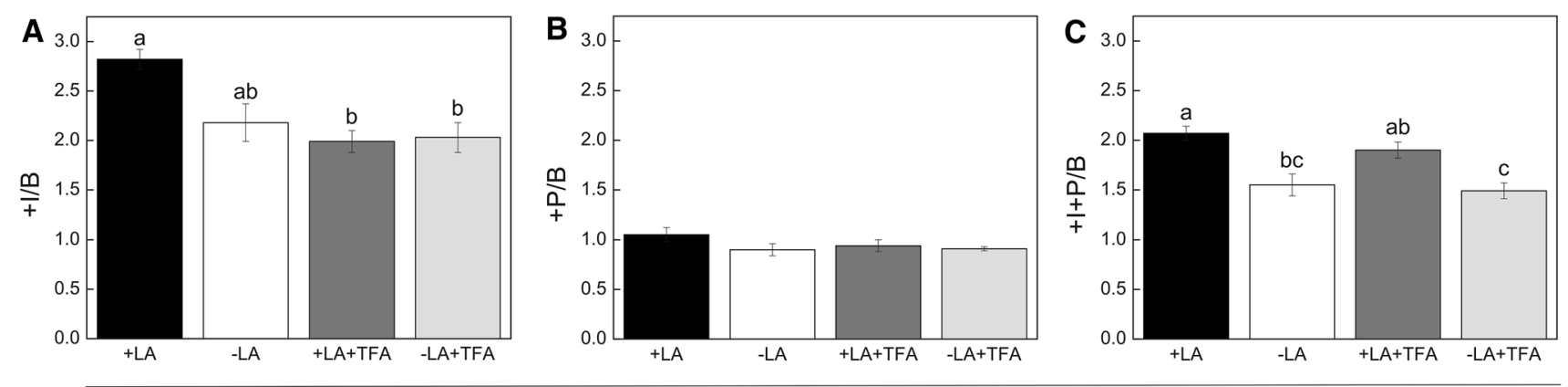

Experimental groups

Fig. 1 Glucose uptake in the soleus muscle presented as relative response to basal conditions: a insulin, b palmitate, and $\mathbf{c}$ insulin + palmitate. Data are means $\pm \mathrm{SEM}, n=4$ per group. Statistical differences between different groups were established by twoway ANOVA $(2 \times 2)$, followed by Scheffe's test. Bars with different superscript letters are significantly different $(\mathrm{p}<0.05)$. Experimental groups: ${ }^{+}$LA: enriched with LA; ${ }^{-}$LA: deprived of LA; ${ }^{+} \mathrm{LA}+\mathrm{TFA}$ : ${ }^{+}$LA supplemented with TFA-enriched oil; ${ }^{-}$LA + TFA: ${ }^{-}$LA supplemented with TFA-enriched oil. $L A$ linoleic acid, TFA trans fatty acids, $B$ basal, $+I$ with the addition of insulin, $+P$ with the addition of palmitate 

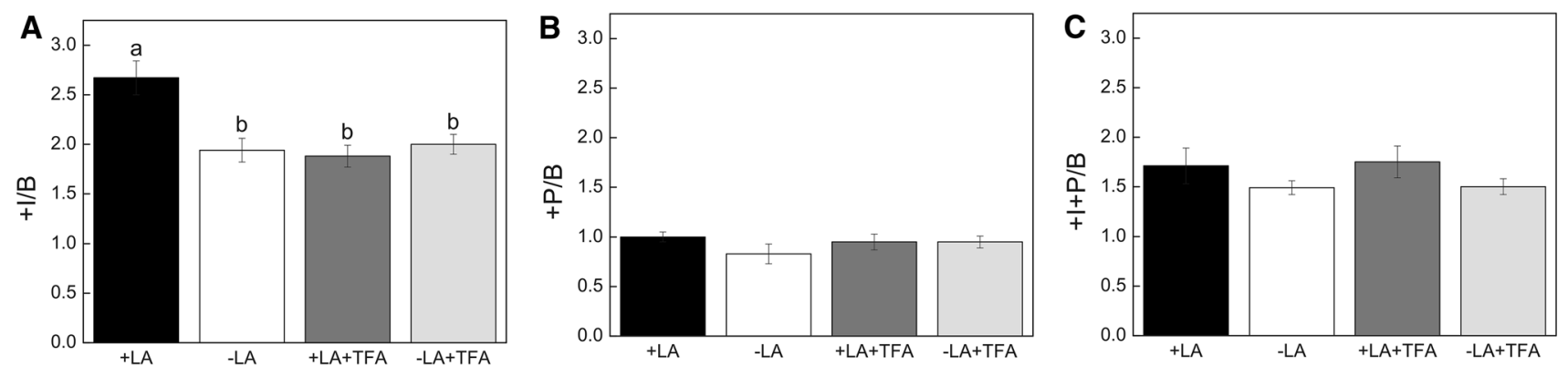

Experimental groups

Fig. 2 Glucose incorporation in the soleus muscle presented as relative response to basal conditions: a insulin, $\mathbf{b}$ palmitate, and $\mathbf{c}$ insulin + palmitate. Data are means \pm SEM, $n=4$ per group. Statistical differences between different groups were established by twoway ANOVA $(2 \times 2)$, followed by Scheffe's test. Bars with different superscript letters are significantly different $(p<0.05)$. Experimental groups: ${ }^{+}$LA: enriched with LA; ${ }^{-L A}$ : deprived of LA; ${ }^{+} \mathrm{LA}+\mathrm{TFA}$ : ${ }^{+}$LA supplemented with TFA-enriched oil; ${ }^{-}$LA + TFA: ${ }^{-}$LA supplemented with TFA-enriched oil. LA linoleic acid, TFA trans fatty acids, $B$ basal, $+I$ with the addition of insulin, $+P$ with the addition of palmitate
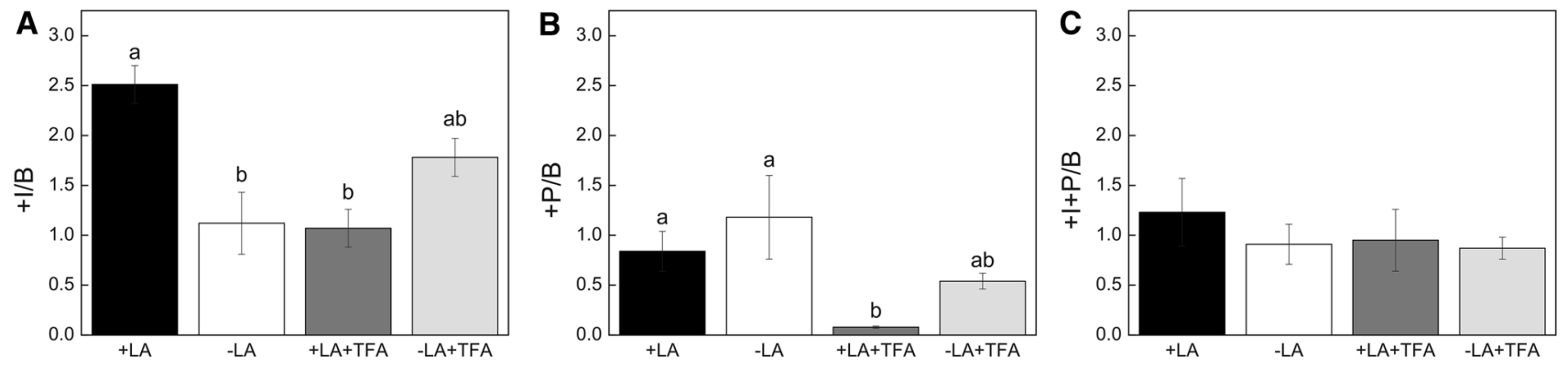

Experimental groups

Fig. 3 Glucose oxidation in the soleus muscle presented as relative response to basal conditions: a insulin, $\mathbf{b}$ palmitate, and $\mathbf{c}$ insulin + palmitate. Data are means \pm SEM, $n=4$ per group. Statistical differences between different groups were established by two-way ANOVA $(2 \times 2)$, followed by Scheffe's test. Bars with different superscript letters are significantly different $(p<0.05)$. Experimental groups: ${ }^{+} \mathrm{LA}$ : enriched with LA; ${ }^{-} \mathrm{LA}$ : deprived of LA; ${ }^{+} \mathrm{LA}+\mathrm{TFA}$ : ${ }^{+}$LA supplemented with TFA-enriched oil; ${ }^{-}$LA + TFA: ${ }^{-}$LA supplemented with TFA-enriched oil. $L A$ linoleic acid, TFA trans fatty acids, $B$ basal, $+I$ with the addition of insulin, $+P$ with the addition of palmitate presence of insulin $(+\mathrm{I}+\mathrm{P})$ significantly inhibited the hormone effect $(+\mathrm{I})$ in the ${ }^{+} \mathrm{LA}$ and ${ }^{-} \mathrm{LA}+\mathrm{TFA}$ groups.

Glycogen synthesis in the soleus muscle was not different among the groups under basal conditions. Insulin stimulation significantly increased the glycogen synthesis in all experimental groups. However, the final values were lowered in the ${ }^{-} \mathrm{LA},{ }^{+} \mathrm{LA}+\mathrm{TFA}$, and ${ }^{-} \mathrm{LA}+\mathrm{TFA}$ groups when compared with the ${ }^{+}$LA group (Fig. 4a). Palmitate treatment in the presence of insulin $(+\mathrm{I}+\mathrm{P})$ attenuated the stimulation of glycogen synthesis by this hormone in the ${ }^{+} \mathrm{LA}$ and ${ }^{-} \mathrm{LA}+\mathrm{TFA}$ groups. The inhibitory effect of palmitate was not observed in the ${ }^{-} \mathrm{LA}$ and ${ }^{+} \mathrm{LA}+\mathrm{TFA}$ groups.

\section{Discussion}

This is the first study that shows the effects of TFA on glucose metabolism and insulin sensitivity in rats submitted to diets containing different LA levels. Basal and insulin-stimulated glucose uptake and metabolism were investigated in skeletal muscle, treated or not with palmitic acid, an inducer of insulin resistance state. We observed some interactions between dietary TFA and LA, under the different conditions analyzed (absence or presence of insulin and/or palmitic acid), in regulating muscle glucose uptake and utilization. These effects were associated with modifications in the FA profile induced by the different diets both in the 

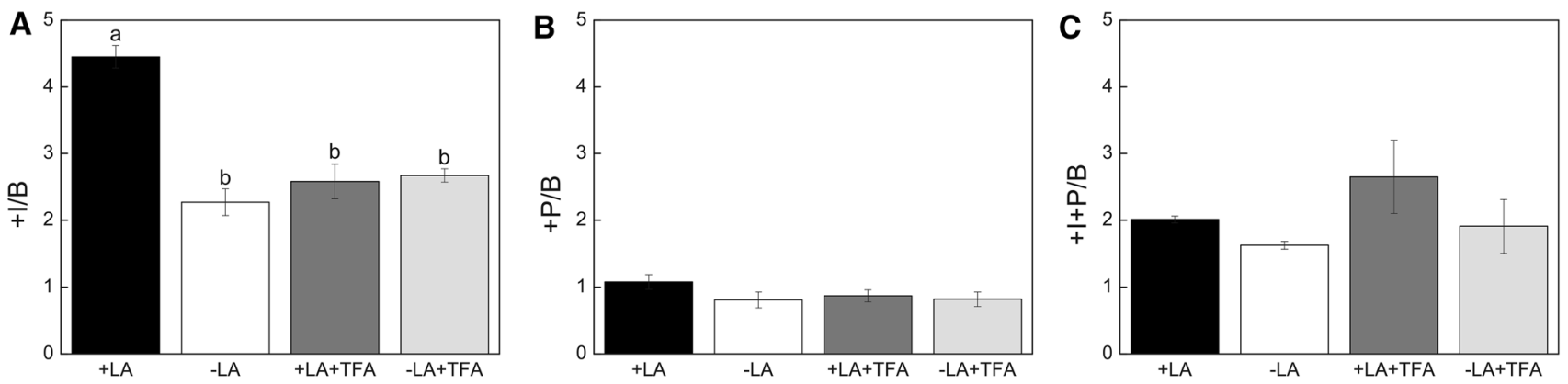

Experimental groups

Fig. 4 Glycogen synthesis in the soleus muscle presented as relative response to basal conditions: a insulin, b palmitate, and $\mathbf{c}$ insulin + palmitate. Data are means \pm SEM, $n=4$ per group. Statistical differences between different groups were established by two-way ANOVA $(2 \times 2)$, followed by Scheffe's test. Bars with different superscript letters are significantly different $(p<0.05)$. Experimental

serum and skeletal muscle, suggesting that lipid metabolization and incorporation into plasma membrane are important determining factors of glucose metabolism and insulin sensitivity.

TFA increased the basal glucose utilization in skeletal muscle regardless of the LA status. However, TFA diminished the insulin-stimulated glucose metabolism. TFA have been widely related to deleterious properties on glucose metabolism in different experimental animal models [10-12]. Nevertheless, lack of effect on glucose metabolism due to TFA supplementation has also been observed by different authors $[8,42,43]$, and, even more, we have previously demonstrated that conjugated linoleic acids (a positional and geometrical isomer) have a positive impact on glucose utilization in soleus muscle [14]. Since the TFA composition of the diets was not similar in these studies, the specific type of TFA might play an important role in glucose metabolism.

Recently, we reported [9] that rats fed a LA-deprived diet supplemented with industrial TFA presented diverse alterations in lipid metabolism. Several of these alterations have been associated with changes in glucose utilization and glycogen synthesis, even with low serum glucose levels, in different experimental animal models [18, $44,45]$. To our knowledge, studies focusing on the effects of TFA on glucose metabolism in experimental animal models fed an unbalanced diet of LA have not been published. Thus, in the present work, we focused on the effects of TFA at two different LA dietary levels: the first dietary treatment aimed to mimic the FA profile of the western diet (rich in LA), and the second was designed to limit LA disposal (deprived of LA). Specifically, the diets were based on the recommendations by Reeves et al. [28], while modifying the oil source as previously groups: ${ }^{+} \mathrm{LA}$ : enriched with LA; ${ }^{-} \mathrm{LA}$ : deprived of LA; ${ }^{+} \mathrm{LA}+\mathrm{TFA}$ : ${ }^{+}$LA supplemented with TFA-enriched oil; ${ }^{-}$LA + TFA: ${ }^{-}$LA supplemented with TFA-enriched oil. LA linoleic acid, TFA trans fatty acids, $B$ basal, $+I$ with the addition of insulin, $+P$ with the addition of palmitate

recommended in the AIN-76 diet [29]. Related to this, Lien et al. [46] concluded that feeding rats either an AIN-93G or an AIN-76 diet for 13 weeks promoted normal growth and development and did not cause deleterious effects. These results agree with the findings of the present work. We observed that the average daily food intake was similar among the groups; however, animals fed a diet supplemented with TFA showed increased body weight gain. Although the ALA level is low and the ratio of LA/ALA is not the recommended one in the corn oil [28], the control animals did not show alterations in the biomarkers of EFA deficiency, such as increasing the mead acid levels and triene/tetraene ratio. In contrast, animals fed coconut oil had significant changes in these parameters. We have previously described similar results in deficiency biomarkers in other tissues, such as liver, adipose tissue, and brain $[9,33]$. In addition, the TFA incorporation was not influenced by the dietary LA levels, but depended on the trans double bond position [7]. In the present work, in serum and muscle, we observed a trans-18:1 isomer retention pattern similar to the one found in our previous publication [9]. The relative conversion of LA to AA was not modified among the groups. Nevertheless, the $\Delta 9-, \Delta 6$-, and $\Delta 5$-desaturase indexes were differently modified by LA deprivation. Thus, the $\Delta 9$ - and $\Delta 6$-desaturase indexes were increased and this effect was probably a consequence of high intake of SFA and low intake of LA in the LA-deprived groups. Similar effects have been reported by other authors [34, 47]. Moreover, although the intake of ALA in the deprived groups was lower, the bioconversion to DHA (DHA/ ALA ratio) did not differ among the groups, and even more it was higher in ${ }^{-} \mathrm{LA}+\mathrm{TFA}$ group. It is probable that the substrate flux through the desaturase enzyme was 
displaced to the n-3 family as a consequence of LA deprivation, in agreement with the results of Gibson et al. [48]. On the other hand, several studies have shown that TFA impair EFA microsomal desaturation and elongation to their LC-PUFA metabolites, either by competition between the substrates or among their reaction products [49-51]. Despite that in the present work we did not observe this effect in serum or muscle, it was observed in the liver (data not shown).

Serum glucose levels were decreased by TFA. This was associated to an increased glucose uptake and oxidation in muscle under basal conditions. There are few studies showing some potential beneficial effects of TFA on glucose utilization. In a previous work [14], we found that, under basal conditions, a CLA mixture (positional and geometrical isomers) increased glucose oxidation in the soleus muscle of animals fed diets enriched in or deprived of LA. Moreover, in animals fed LA-deprived diet, glucose uptake and metabolism was enhanced by CLA supplementation. In the present work, the beneficial effects observed in the TFAsupplemented animals could be related to the $9 c, 11 t$-CLA isomer. This FA was not present in the diets; however, it was produced from the $11 t-18: 1$ and significantly retained into the tissues. In this regard, Battacharya et al. [52] observed decreased glucose and insulin levels in male mice fed a high-fat diet containing $0.5 \%$ of commercial CLA with equimolecular amounts of $9 c, 11 t$-CLA and $10 t, 12 c$ CLA. Likewise, Houseknecht et al. [15] demonstrated, in Zucker diabetic rats, that CLA normalized glucose tolerance, reduced hyperinsulinemia, and lowered circulating free fatty acids. Moreover, Choi et al. [17] found, in rats fed a high-fat diet supplemented with $9 c, 11 t$-enriched CLA-mix, 10t,12c-enriched CLA-mix, or a 30:40 CLAmix of each isomer, respectively, that both $9 c, 11 t$-CLA and $10 t, 12 c$-CLA activated the insulin signaling pathway.

The animals supplemented with TFA presented a lower insulin-stimulated glucose uptake, incorporation and oxidation, and glycogen synthesis than nonsupplemented animals. Other authors [53] found, in offspring of rats fed a diet containing TFA during pregnancy and lactation, which continued receiving TFA diet until 90 days after birth, that glucose levels remained normal because of a compensatory effect of higher levels of serum adiponectin associated with higher levels of insulin and its receptor, suggesting increased insulin resistance state induced by TFA. Increased basal insulin secretion in rats treated with dietary TFA can occur and explain, at least in part, the reduced plasma glucose levels and the elevated basal glucose uptake and metabolism in skeletal muscle observed in the present work. Moreover, the insulin resistance induced by TFA could be related to modifications in the polyunsaturated FA (PUFA) profile in muscle cells [18, 44, 45]. On the other hand, Kavanagh et al. [12], in monkeys fed a diet containing trans isomers (8\% of energy), observed insulin resistance associated with an impairment of the signal transduction downstream to the insulin receptor binding.

Preincubation with palmitate reduces glucose uptake and incorporation in skeletal muscle under basal and insulin-stimulated conditions [14, 38, 54], mimicking an in vivo insulin resistance state induced by a high disposal of plasma-free FA. This state occurs in several pathological conditions, including obesity, type 2 diabetes mellitus, and metabolic syndrome. Accordingly, animals fed a high-fat diet develop insulin resistance and hyperinsulinemia [22, $23,55]$. These effects depend on the type of dietary FA and on potential changes in membrane phospholipids, as well as on the bioactive lipid metabolites generated by the different FA [56, 57]. For example, long-chain saturated FA, including palmitate and stearate, are associated with impairment in insulin sensitivity in skeletal muscle and isolated muscle cells via a decrease in the PUFA content in membrane phospholipids and an increase in the intramyocellular lipid derivatives; these changes are associated with deleterious effects on the skeletal muscle cells $[56,58]$. In our study, palmitate treatment did not inhibit glucose uptake and incorporation or glycogen synthesis in the absence of insulin in the control or the TFA-supplemented animals. However, this fatty acid clearly impaired glucose uptake and metabolism under insulin-stimulated conditions in the control and ${ }^{-} \mathrm{LA}+\mathrm{TFA}$ groups. These results indicate that, under insulin-stimulated conditions, TFA partially attenuated the palmitate inhibition of muscle glucose uptake and metabolism in the ${ }^{+} \mathrm{LA}+$ TFA group. This effect may be attributed to two different circumstances acting together. The first one, muscle plasma membrane modifications, which are known to modulate glucose uptake and metabolism. In this regards, the amount of PUFA in the ${ }^{+} \mathrm{LA}+\mathrm{TFA}$ group is higher than the ${ }^{-} \mathrm{LA}+\mathrm{TFA}$ group, regardless of the TFA supplementation, and it is well reflected in the differences found in the $\sum$ PUFA/ $\sum$ SFA and LA/ $\sum$ TFA ratios. Similar effects have been observed by other authors on membrane enrichment with PUFA, which increased the GLUT-1 and GLUT- 4 contents in the plasma membrane, as well as the membrane fluidity [45]. It also improved insulin signaling among several other proposed mechanisms [59]. The second one, probably the bioconversion of $11 t-18: 1$ to $9 c, 11 t$-CLA in the ${ }^{+} \mathrm{LA}+\mathrm{TFA}$ group, but not in the ${ }^{+} \mathrm{LA}$ group, is highlighting the beneficial effect of CLA. In this regard, we have demonstrated [14] that in soleus muscle CLA prevented the palmitate inhibition of muscle glucose uptake and incorporation under insulin-stimulated conditions and this effect was associated, at least in part, to different lipid derivative production.

Finally, the present results demonstrate different and complex mechanisms of how TFA, insulin, and/or palmitate interact mutually to modify muscle glucose utilization 
depending on the dietary levels of LA. We conclude that the effect of TFA on glucose metabolism and insulin sensitivity depends mainly on the changes in the FA profile induced by dietary LA, as well as, on the specific type of isomer consumed with the diet and present in the tissues. These findings can help explain the overall controversial TFA effects found in previous studies.

Acknowledgements We wish to thank Walter DaRú for his technical assistance. We also thank Universidad Nacional del Litoral-Cursos de Acción para la Investigación y Desarrollo (CAI+D 501201101 00165 LI)-Secretaría de Ciencia y Técnica-UNL, Consejo Nacional de Investigaciones Científicas y Técnicas (PIP CONICET No. 112200801-02831), FAPESP (Fundação de Amparo à Pesquisa do Estado de São Paulo) and CONICET Resol. No. 473/11, for their financial support to the collaborative research program between the Universidad Nacional del Litoral and the Universidade de São Paulo.

\section{Compliance with Ethical Standards}

Conflict of interest There are no conflicts of interest in this study.

Ethical approval The experimental procedures were approved by the Ethics Committee of the School of Biochemistry and by the Ethics Committee of the Institute of Biomedical Sciences, University of Sao Paulo. Both followed the Guide for the Care and Use of Laboratory Animals.

\section{References}

1. Fedacko J, Vargova V, Singh RB, Anjum B (2012) Association of high w-6 / w-3 fatty acid ratio diet with causes of death due to noncommunicable diseases among urban decedents in north India. Open Nutraceuticals J 5:113-123

2. Lee JH, Fukumoto M, Nishida H, Ikeda I, Sugano M (1989) The interrelated effects of $n-6 / n-3$ and polyunsaturated/saturated ratios of dietary fats on the regulation of lipid metabolism in rats. J Nutr 119:1893-1899

3. Broughton KS, Wade JW (2002) Total fat and (n-3):(n-6) fat ratios influence eicosanoid production in mice. J Nutr 132:88-94

4. Igarashi M, Gao F, Kim HW, Ma K, Bell JM, Rapoport SI (2009) Dietary n-6 PUFA deprivation for 15 weeks reduces arachidonic acid concentrations while increasing n-3 PUFA concentrations in organs of post-weaning male rats. Biochim Biophys Acta 1791:132-139

5. Allmann DW, Gibson DM (1965) Fatty acid synthesis during early linoleic acid deficiency in the mouse. J Lipid Res 6:51-62

6. Colandre ME, Diez RS, Bernal CA (2003) Metabolic effects of trans fatty acids on an experimental dietary model. Br J Nutr 89:631-639

7. Dorfman SE, Laurent D, Gounarides JS, Li X, Mullarkey TL, Rocheford EC, Sari-Sarraf F, Hirsch EA, Hughes TE, Commerford SR (2009) Metabolic implications of dietary trans-fatty acids. Obesity (Silver Spring) 17:1200-1207

8. Bernal CA, Rovira J, Colandre ME, Cusso R, Cadefau JA (2006) Effects of dietary cis and trans unsaturated and saturated fatty acids on the glucose metabolites and enzymes of rats. Br J Nutr 95:947-954

9. Fariña AC, González MA, Scalerandi MV, Bernal CA (2015) Effect of trans fatty acids on the nutritional status and lipid metabolism in rats fed linoleic acid enriched and deficient diets. Eur J Lipid Sci Technol 117:933-944

10. Ibrahim A, Natrajan S, Ghafoorunissa R (2005) Dietary transfatty acids alter adipocyte plasma membrane fatty acid composition and insulin sensitivity in rats. Metabolism 54:240-246

11. Silveira Osso F, Bello Moreira AS, Teixeira Teixeira M, Oliveira Pereira R, Tavares do Carmo MG, Sanchez Moura A (2008) Trans fatty acids in maternal milk lead to cardiac insulin resistance in adult offspring. Nutrition 24(7-8):727-732

12. Kavanagh K, Jones KL, Sawyer J, Kelley K, Carr JJ, Wagner JD, Rudel LL (2007) Trans fat diet induces abdominal obesity and changes in insulin sensitivity in monkeys. Obesity 15:1675-1684

13. Ryder JW, Portocarrero CP, Song XM, Cui L, Yu M, Combatsiaris T, Galuska D, Bauman DE, Barbano DM, Charron MJ, Zierath JR, Houseknecht KL (2001) Isomer-specific antidiabetic properties of conjugated linoleic acid. Improved glucose tolerance, skeletal muscle insulin action, and UCP-2 gene expression. Diabetes 50:1149-1157

14. Fariña AC, Hirabara S, Sain J, Latorre ME, González MA, Curi R, Bernal CA (2014) Conjugated linoleic acid improves glucose utilization in the soleus muscle of rats fed linoleic acid-enriched and linoleic acid-deprived diets. Nutr Res 34(1092):1100

15. Houseknecht KL, Vanden Heuvel JP, Moya-Camarena SY, Portocarrero CP, Peck LW, Nickel KP, Belury MA (1998) Dietary conjugated linoleic acid normalizes impaired glucose tolerance in the Zucker diabetic fatty fa/fa rat. Biochem Biophys Res Commun 244:678-682

16. Choi JS, Jung MH, Park HS, Song J (2004) Effect of conjugated linoleic acid isomers on insulin resistance and mRNA levels of genes regulating energy metabolism in high-fat-fed rats. Nutrition 20:1008-1017

17. Choi JS, Koh IU, Jung MH, Song J (2007) Effects of three different conjugated linoleic acid preparations on insulin signalling, fat oxidation and mitochondrial function in rats fed a high-fat diet. Br J Nutr 98:264-275

18. Natarajan S, Ibrahim A (2005) Dietary trans fatty acids alter diaphragm phospholipid fatty acid composition, triacylglycerol content and glucose transport in rats. Br J Nutr 93:829-833

19. Sakamoto K, Holman GD (2008) Emerging role for AS160/ TBC1D4 and TBC1D1 in the regulation of GLUT4 traffic. Am J Physiol Endocrinol Metab 295:E29-E37

20. Hirabara SM, Curi R, Maechler P (2010) Saturated fatty acidinduced insulin resistance is associated with mitochondrial dysfunction in skeletal muscle cells. J Cell Physiol 222:187-194

21. Roden M (2004) How Free Fatty Acids Inhibit Glucose Utilization in Human Skeletal Muscle. Physiology 19(3):92-96

22. Randle PJ, Garland PB, Hales CN, Newsholme EA (1963) The glucose fatty-acid cycle. Its role in insulin sensitivity and the metabolic disturbances of diabetes mellitus. The Lancet 1:785-789

23. Hirabara SM, Gorjao R, Vinolo MA, Rodrigues AC, Nachbar RT, Curi R (2012) Molecular targets related to inflammation and insulin resistance and potential interventions. J Biomed Biotechnol 2012:379024

24. Hill EG, Johnson SB, Holman RT (1979) Intensification of essential fatty acid deficiency in the rat by dietary trans fatty acids. J Nutr 109:1759-1765

25. Hill EG, Johnson SB, Lawson LD, Mahfouz MM, Holman RT (1982) Perturbation of the metabolism of essential fatty acids by dietary partially hydrogenated vegetable oil. Proc Natl Acad Sci U S A 79:953-957

26. Privett OS, Phillips F, Shimasaki H, Nozawa T, Nickell EC (1977) Studies of effects of trans fatty acids in the diet on lipid metabolism in essential fatty acid deficient rats. Am J Clin Nutr 30:1009-1017 
27. Bayne K (1996) Revised Guide for the Care and Use of Laboratory Animals available. American Physiological Society. Physiologist 39:199, 208-199, 211

28. Reeves PG, Nielsen FH, Fahey GC Jr (1993) AIN-93 purified diets for laboratory rodents: final report of the American Institute of Nutrition ad hoc writing committee on the reformulation of the AIN-76A rodent diet. J Nutr 123:1939-1951

29. Report of the American Institute of Nutrition Ad Hoc Committee on Standards for Nutritional Studies (1977) J Nutr 107:1340-1348

30. Bligh EG, Dyer WJ (1959) A rapid method of total lipid extraction and purification. Can J Biochem Physiol 37:911-917

31. ISO 5509(E) (2000) Animal and vegetable fats and oils. Preparation of methyl esters of fatty acids

32. AOCS Official Method Ce 1j-07 (2007) Official methods and recommended practices of the AOCS, 6th edition, AOCS, Champaign

33. Fariña AC, González MA, Latorre ME, Bernal CA (2013) Efectos de los conjugados del ácido linoleico sobre la incorporación tisular de ácidos grasos y metabolismo lipídico en ratas deficientes en ácidos grasos esenciales. FABICIB 17, 85-112

34. Warensjo E, Riserus U, Gustafsson IB, Mohsen R, Cederholm T, Vessby B (2008) Effects of saturated and unsaturated fatty acids on estimated desaturase activities during a controlled dietary intervention. Nutr Metab Cardiovasc Dis 18:683-690

35. Crettaz M, Prentki M, Zaninetti D, Jeanrenaud B (1980) Insulin resistance in soleus muscle from obese Zucker rats. Involvement of several defective sites. Biochem J 186:525-534

36. Massao HS, de Oliveira Carvalho CR, Mendonca JR, Piltcher HE, Fernandes LC, Curi R (2003) Palmitate acutely raises glycogen synthesis in rat soleus muscle by a mechanism that requires its metabolization (Randle cycle). FEBS Lett 541:109-114

37. Challiss RA, Espinal J, Newsholme EA (1983) Insulin sensitivity of rates of glycolysis and glycogen synthesis in soleus, stripped soleus, epitrochlearis, and hemi-diaphragm muscles isolated from sedentary rats. Biosci Rep 3:675-679

38. Thompson AL, Lim-Fraser MY, Kraegen EW, Cooney GJ (2000) Effects of individual fatty acids on glucose uptake and glycogen synthesis in soleus muscle in vitro. Am J Physiol Endocrinol Metab 279:E577-E584

39. Leighton B, Budohoski L, Lozeman FJ, Challiss RA, NEWSHOLME EA (1985) The effect of prostaglandins E1, E2 and F2 alpha and indomethacin on the sensitivity of glycolysis and glycogen synthesis to insulin in stripped soleus muscles of the rat. Biochem J 227:337-340

40. Espinal J, Dohm GL, NEWSHOLME EA (1983) Sensitivity to insulin of glycolysis and glycogen synthesis of isolated soleusmuscle strips from sedentary, exercised and exercise-trained rats. Biochem J 212:453-458

41. DeGroot M (1986) Probability and statistics. Addison-Wesley Publishing Company, Reading

42. Lovejoy JC, Smith SR, Champagne CM, Most MM, Lefevre M, DeLany JP, Denkins YM, Rood JC, Veldhuis J, Bray GA (2002) Effects of diets enriched in saturated (palmitic), monounsaturated (oleic), or trans (elaidic) fatty acids on insulin sensitivity and substrate oxidation in healthy adults. Diabetes Care 25:1283-1288

43. Louheranta AM, Turpeinen AK, Vidgren HM, Schwab US, Uusitupa MI (1999) A high-trans fatty acid diet and insulin sensitivity in young healthy women. Metabolism 48:870-875
44. Simopoulos AP (1994) Is insulin resistance influenced by dietary linoleic acid and trans fatty acids? Free Radic Biol Med $17: 367-372$

45. de Santa Olalla LM, Sánchez Muniz FJ, Vaquero MP (2009) N-3 fatty acids in glucose metabolism and insulin sensitivity. Nutr Hosp 24:113-127

46. Lien EL, Boyle FG, Wrenn JM, Perry RW, Thompson CA, Borzelleca JF (2001) Comparison of AIN-76A and AIN-93G diets: a 13-week study in rats. Food Chem Toxicol 39:385-392

47. Pugh EL, Kates M (1984) The dietary regulation of acyltransferase and desaturase activities in microsomal membranes of rat liver. Lipids 19:48-55

48. Gibson RA, Neumann MA, Lien EL, Boyd KA, Tu WC (2013) Docosahexaenoic acid synthesis from alpha-linolenic acid is inhibited by diets high in polyunsaturated fatty acids. Prostaglandins Leukot Essent Fatty Acids 88:139-146

49. Brenner RR, Peluffo RO (1969) Regulation of unsaturated fatty acids biosynthesis. I. Effect of unsaturated fatty acid of 18 carbons on the microsomal desaturation of linoleic acid into gamma-linolenic acid. Biochim Biophys Acta 176:471-479

50. Larque E, Garcia-Ruiz PA, Perez-Llamas F, Zamora S, Gil A (2003) Dietary trans fatty acids alter the compositions of microsomes and mitochondria and the activities of microsome delta6fatty acid desaturase and glucose-6-phosphatase in livers of pregnant rats. J Nutr 133:2526-2531

51. Kummerow FA, Zhou Q, Mahfouz MM, Smiricky MR, Grieshop CM, Schaeffer DJ (2004) Trans fatty acids in hydrogenated fat inhibited the synthesis of the polyunsaturated fatty acids in the phospholipid of arterial cells. Life Sci 74:2707-2723

52. Bhattacharya A, Rahman MM, Sun D, Lawrence R, Mejia W, McCarter R, O'Shea M, Fernandes G (2005) The combination of dietary conjugated linoleic acid and treadmill exercise lowers gain in body fat mass and enhances lean body mass in high fatfed male Balb/C mice. J Nutr 135:1124-1130

53. Pisani LP, Oyama LM, Bueno AA, Biz C, Albuquerque KT, Ribeiro EB, Oller do Nascimento CM (2008) Hydrogenated fat intake during pregnancy and lactation modifies serum lipid profile and adipokine mRNA in 21-day-old rats. Nutrition $24: 255-261$

54. Alkhateeb H, Chabowski A, Glatz JF, Luiken JF, Bonen A (2007) Two phases of palmitate-induced insulin resistance in skeletal muscle: impaired GLUT4 translocation is followed by a reduced GLUT4 intrinsic activity. Am J Physiol Endocrinol Metab 293:E783-E793

55. Storlien LH, Baur LA, Kriketos AD, Pan DA, Cooney GJ, Jenkins AB, Calvert GD, Campbell LV (1996) Dietary fats and insulin action. Diabetologia 39(6):621-631

56. Schmitz-Peiffer C (2000) Signalling aspects of insulin resistance in skeletal muscle: mechanisms induced by lipid oversupply. Cell Signal 12:583-594

57. Andersson A, Nalsen C, Tengblad S, Vessby B (2002) Fatty acid composition of skeletal muscle reflects dietary fat composition in humans. Am J Clin Nutr 76:1222-1229

58. Cooney GJ, Thompson AL, Furler SM, Ye J, Kraegen EW (2002) Muscle long-chain acyl CoA esters and insulin resistance. Ann N Y Acad Sci 967:196-207

59. Dimopoulos N, Watson M, Sakamoto K, Hundal HS (2006) Differential effects of palmitate and palmitoleate on insulin action and glucose utilization in rat L6 skeletal muscle cells. Biochem J 399:473-481 